\title{
PETROGLIFOS PODOMORFOS DE GALICIA E INVESTIDURAS REALES CÉLTICAS: ESTUDIO COMPARATIVO
}

\author{
POR \\ MARCO V. GARCÍA QUINTELA \\ Área de Historia Antigua \\ MANUEL SANTOS ESTÉVEZ \\ Laboratorio de Arqueoloxía e Formas Culturais \\ Universidade de Santiago de Compostela
}

PALABRAS CLAVE: Edad del Bronce. Edad del Hierro. Petroglifos. Ritos celtas. Pontevedra (provincia). Orense (provincia).

KEY WORDS: Bronze age. Iron age. Petroglyphs. Celt rites. Pontevedra (province). Orense (province).

\section{RESUMEN}

Desde dos disciplinas distintas: la antropología histórica y la arqueología, se abordan algunos rituales de investidura real en el mundo indoeuropeo. Partimos de referencias literarias y etnográficas a costumbres y ritos propios de la toma de posesión de su cargo por los reyes en los que destaca el detalle de que debía poner su pie sobre cierta roca. Relacionamos estos testimonios con la presencia en Galicia de petroglifos con podomorfos de las Edades del Bronce y del Hierro, y se formula la hipótesis de que en ellos se celebrasen ceremonias del tipo referido en los textos.

\section{SUMMARY}

Royal coronation rituals in the Indo-European world are discussed from the points of view of two different disciplines, historical anthropology and archaeology. The paper starts with literary and ethnographic references to coronation rituals and rites, with special emphasis with that of placing the foot on a special rock. The relationships between these sources and the presence of carved rock footprints in Galicia, dating from the Bronze and Iron Ages, are then analysed and the possibility that these carvings reflect the ceremonies described in the texts is discussed.

\section{UNA NOTICIA ARQUEOLÓGICA EN MAR- TÍN DE DUMIO}

El monje y erudito San Martín de Dumio, obispo de Braga en el siglo vi d. C. menciona y reprueba al mismo tiempo ciertos usos de los campesinos de su tierra:

Nam ad petras et ad arbores et ad fontes et per trivia cereolos incendere, quid est aliud nisi cultura diaboli?... Vulcanalia et Kalendas observare, mensas ornare, et lauros ponere, et pedem observare, et fundere in foco super truncum frugem et vinum, et panem in fontem mit tere, quid est aliud nisi cultura diaboli? (De Correctione rusticorum, 16.2)
Los ritos en torno a piedras cuentan con otros testimonios de la misma época (Taboada, 1965, 11) y han pasado a la jerga de los estudiosos como «culto a las piedras... árboles... aguas... encrucijadas» ${ }^{1}$. Pero esas expresiones implican aceptar la parte, lo que nos cuenta Martín y otros testimonios comparables, como la totalidad de una secuencia ritual de la que la noticia comentada solo sería sucinto residuo.

Normalmente catalogadas como supersticiosas (López Pereira, 1996, 55-67, 87 y 91-95; Alonso del Real, 1971); estas prácticas lo son en el uso griego analizado por Plutarco en su tratado Peri Deisidaimonías o por Tito Livio (XXV, 1, 6-12) cuando califica de supersticiosas las acciones de mujeres $\mathrm{y}$ campesinos opuestas a la religio de los magistrados ordinarios (Calderone, 1972). Aunque no utilice $s u$ perstitio, Martín se inscribe en esta corriente de pensamiento cuando relega prácticas opuestas a la religión oficial con un criterio que tiene mucho de clasista.

En ninguno de los casos mencionados se describen ni se comprenden los ritos ajenos. Simplemente

1 Véase el estudio clásico de Taboada, 1965. En sentido análogo otro clásico es López Cuevillas y Bouza, 1929, 121166 , sobre la «ofiolatría», una perspectiva más actual sobre el tema en Criado, 1986, y Llinares, 1990. Sobre las aguas y fuentes García Fernández-Albalat, 1986, y Díez de Velasco, 1998. Sobre el «culto a las encrucijadas», Bermejo, 1986, 193-230. El más evidente representante de esta corriente es Eliade, 1974, I, 253-75, con el mérito de compilar noticias de interés en torno a cada objeto o tipo de objetos.

Trabajo realizado en el marco del Proyecto de Investigación PB 97-0549 Sociedad y Cultura Material en la Protohistoria del Noroeste Peninsular, subvencionado por el Programa Sectorial de Promoción General del Conocimiento de la Secretaría de Estado de Universidades, Investigación y Desarrollo. E-mail de los autores phmarco@usc.es phsantos@usc.es. Agradecimientos a Paula Ballesteros y Raquel López, por su ayuda en los trabajos de campo; a Anxo Rodríguez por el diseño de los mapas; a Jesús M. Pérez Centeno, Rosa Brañas, Carlos Búa, Felipe Criado, Francisco Marco y César Parcero por sus comentarios críticos y referencias; y a François Delpech por lo mismo y por la inspiración de este artículo que prolonga parte de sus investigaciones. 
se denigran y condenan. No existe la más mínima conciencia de que pudieran tener un sentido. Ahora bien, ni tan siquiera en las formulaciones fetichistas más tradicionales se considera al objeto dotado de poder como un ente autónomo sino, más bien, como depositario de una serie de símbolos insertos en el objeto por medio de unos actos rituales específicos (Lima, 1987). Sin embargo, el estudioso que constata ese «culto a las piedras, fuentes, etc.», mantiene la perspectiva de la etnografía decimonónica y toma la parte por el todo, confunde lo que no está atestiguado o desconoce con lo que no existe, ignora la complicada serie de pensamientos y acciones de corte religioso que pueden estar detrás del objeto más simple. En definitiva, la constatación erudita de un «culto a las piedras» implica una claudicación del pensamiento.

Pero si hemos huir de esa fórmula, ¿cómo debemos interpretar los gestos descritos por Martín y otros que señalan un lugar relevante de las piedras en los sistemas de creencias prerromanos del Noroeste? En este trabajo consideramos que el inventario, sin descartar su necesidad, es insuficiente. ¿Qué nos importa un hecho atestiguado tres, cinco o siete veces, en función de la perfección del catálogo, si desconocemos siempre su sentido? (De ello deriva el descarte, en lo que sigue, de testimonios dudosos y de otros que no hemos podido estudiar in situ).

Ahora bien, aunque no tomemos la parte por el todo, como hace Martín, es buen método tomarse las fuentes en serio y comenzaremos otorgando a Martín el beneficio de la duda. Es decir, los vilipendiados ritos aludidos tendrían que ser conocidos en tiempo de Martín para que la crítica tuviese un destinatario identificable. Es probable, además, que los ritos descritos no fuesen en esa época más que un resto de un rito antiguo más complejo. Y no ha de descartarse la posibilidad de que ese rito estuviese de algún modo vigente en tiempo de Martín quien obvió su descripción llevado por su ánimo enderezador (ver infra).

Partiendo de estas consideraciones vamos a proponer una interpretación de una parte del dossier pétreo relacionado con manifestaciones rituales prerromanas. Se trata de los petroglifos podomorfos, entendiendo que estos objetos pétreos nunca nos va a dar de forma directa una explicación de su uso y sentido.

Tal vez el propio Martín nos ayuda a encontrar un camino si tenemos en cuenta el curioso paralelismo en el orden de las prácticas enumeradas en el texto con el que comenzábamos: ... ad petras et ad arbores et ad fontes..., dice la primera secuencia centrada en objetos, ... et pedem observare, et fundere in foco super truncum frugem et vinum, et pa- nem in fontem mittere..., se dice en otra secuencia centrada en gestos. Esto es, en el segundo y tercer casos, un rito sobre el tronco y un rito relacionado con las fuentes, ¿cabe seguir el paralelo y ver en la atención al pie un gesto relacionado con las rocas? Ateniéndonos en exclusiva al texto no podemos avanzar. Pero la verosimilitud de esta aproximación se refuerza si consideramos el dossier arqueológico de los petroglifos podomorfos: pies y rocas tienen una relación en la que tal vez pensaba Martín.

\section{LOS PETROGLIFOS PODOMORFOS EN EL REGISTRO ARQUEOLÓGICO}

Apenas existen estudios sobre grabados podomorfos en el arte rupestre gallego. Ello se debe a su rareza y a que algunos autores las consideran relativamente modernas cuando se asocian a herraduras (Peña y Vázquez, 1979, 99) o simplemente las consideran todas recientes (Costas y Pereira, 1998, 160161), aunque tales afirmaciones no se argumentan. Para este trabajo nos basaremos en los diseños podomorfos que hemos podido observar sobre el terreno. Consideraremos cinco figuras insculturadas y una originada por la erosión, pero relacionada con una tradición popular que nos servirá para cerrar nuestro análisis.

La dificultad que tiene el estudio de los petroglifos deriva de la aparente descontextualización que presentan las insculturas. Decimos aparente porque es necesario tener en cuenta que el contexto arqueológico es un producto del arqueólogo, que tal contexto no preexiste a la investigación. Para la construcción del necesario contexto nos moveremos dentro del marco de la Arqueología del Paisaje tal como la define Criado (1993a). Otro de los problemas al que nos enfrentamos para estudiar las representaciones de pie humano en rocas al aire libre es la falta de una cronología clara. De todos modos contamos con argumentos para encuadrarlos, con cierta prudencia, entre los inicios del II milenio y el fin de la Edad del Hierro, siendo muy posibles pervivencias en épocas posteriores.

CRITERIOS PARA LA SELECCIÓN DE LOS PETROGLIFOS Y SU CRONOLOGÍA

Antes exponer los datos, explicaremos los criterios seguidos para considerar algunos grabados como podomorfos y a rechazar otros. Así juzgamos como características formales mínimas para considerar un grabado las siguientes: 
- Anchura creciente hacia la parte delantera del pie.

- Parte delantera recta o ligeramente arqueada y parte del talón curva.

- Parte anterior oblicua con respecto al eje longitudinal de la planta del pie, indicando así el tamaño decreciente de los dedos.

Además otros elementos añaden detalles formales a las figuras, como la presencia de dedos y que todos los pediformes estudiados son del tamaño de un pie adulto de tamaño normal $(25 / 30 \mathrm{~cm})$.

Aplicados estos criterios, hemos decidido no incluir varios petroglifos catalogados como podomorfos, se trata de los petroglifos del castro de Santa Tecla en La Guardia (Sobrino, 1946, 131-4), que a nuestro juicio son pequeños rebajes en una laja inclinada posiblemente destinados a facilitar el paso por dicha roca. Tampoco incluimos aquí el petroglifo de Bosque de Cadro en Marín (García Alén y Peña, 1981, 70) por tratarse de dos rebajes que probablemente son rudimentarios molinos rupestres, y por las mismas razones tampoco consideramos la estación de $O$ Espeirón en Mondariz (Costas et al., 1991, 85-116) ${ }^{2}$

Por otra parte, son muy conocidos los podomorfos sobre una de las rocas hoy destruidas del santuario rupestre de Panoias. Estudios recientes divergen en cuanto a su interpretación. Para Alföldy (1997, 214-15) son marcas para el emplazamiento de una estatua de bronce o para indicar la colocación de los pies de un oficiante, para Rodríguez Colmenero (1999,105-6 y 114-5) constituyen uno de los indicios de la existencia de un santuario prerromano en el lugar, aduciendo parajes cercanos con otros podomorfos. Como decíamos más arriba, no es nuestro objetivo establecer un catálogo completo y de límites difíciles de fijar sino avanzar en la interpretación de hechos bien establecidos. En este sentido, los podomorfos de Panoias, claramente insertos en un monumento relacionado con los cultos orientales, responden a las necesidades de ese culto, aunque su origen sea prerromano. Por ello consideramos preferible excluirlos de nuestro examen.

La cronología de este tipo de diseños es el aspecto más problemático del tema, aunque no impe-

\footnotetext{
${ }^{2}$ Mención aparte merecen los petroglifos de Monte $\mathrm{Na}$ raio en Muros (Eiroa y Rey, 1984, 109) y los grabados de Coto Rapado y Os Olleiros (Suárez Otero, 1979, 101-127), que parecen ser pediformes. Esperamos completar con estudios personales in situ de estos y otros podomorfos la muestra que proponemos ahora. No hemos podido localizar la estación de Casa da Rapadoira (Pazos de Borbén). A juzgar por la fotografía publicada (García Alén y Peña, 1981, 187) no parecen representar podomorfos.
}

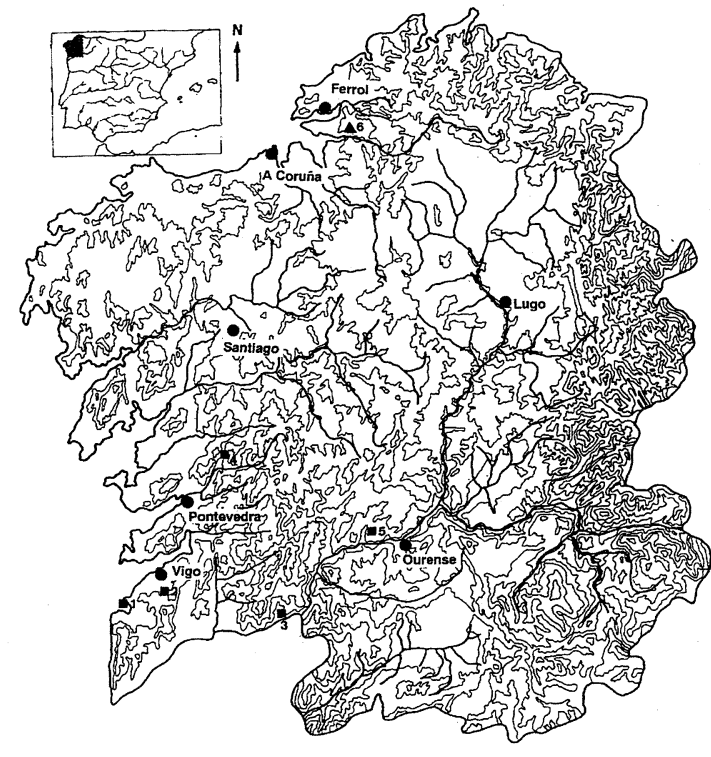

— equidistancia de las curvas de nivel: $200 \mathrm{~m}$.

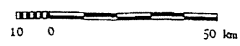

Fig. 1.-Localización de las piedras estudiadas. 1. Monteferro; 2. Pedra da Moura; 3. Castro de San Martiño; 4. Campo de Matabois; 5. A Ferradura; 6. Pena da Elección.

dirá abordar su estudio. Para aproximarnos a la cronología de los grabados nos detendremos en la observación de los motivos con los que comparten panel, en los diseños grabados en rocas adyacentes y en los restantes yacimientos inmediatos. En un contexto más general describiremos yacimientos que, sin estar próximos, pueden guardar relación con las huellas de pie, por ejemplo los yacimientos visibles desde la inscultura. Partiendo de estas consideraciones establecemos dos grupos:

1. Podomorfos de la Edad del Bronce. Incluimos en este grupo los podomorfos que comparten panel con motivos pertenecientes a dicha época, como son las combinaciones circulares.

2. Podomorfos de la Edad del Hierro. Este tipo de figuras aparece compartiendo panel o están en la misma estación que otro tipo de diseños: piletas hemicilíndricas, serpentiformes, herraduras, cruces inscritas, que en diversas zonas aparecen en contextos de la Edad del Hierro, asociados a castros o con inscripciones indígeno-romanas (Criado et al., 1997, 11-9; Santos et al., 1997, 61-80 y Parcero et al., 1998, 159-76).

De todos modos la cronología no es tan fundamental como pudiera parecer. Ello se debe a que el paisaje arqueológico tiene la capacidad de agregar elementos de épocas precedentes incorporándolos y reinterpretándolos dentro de un sistema cohe- 


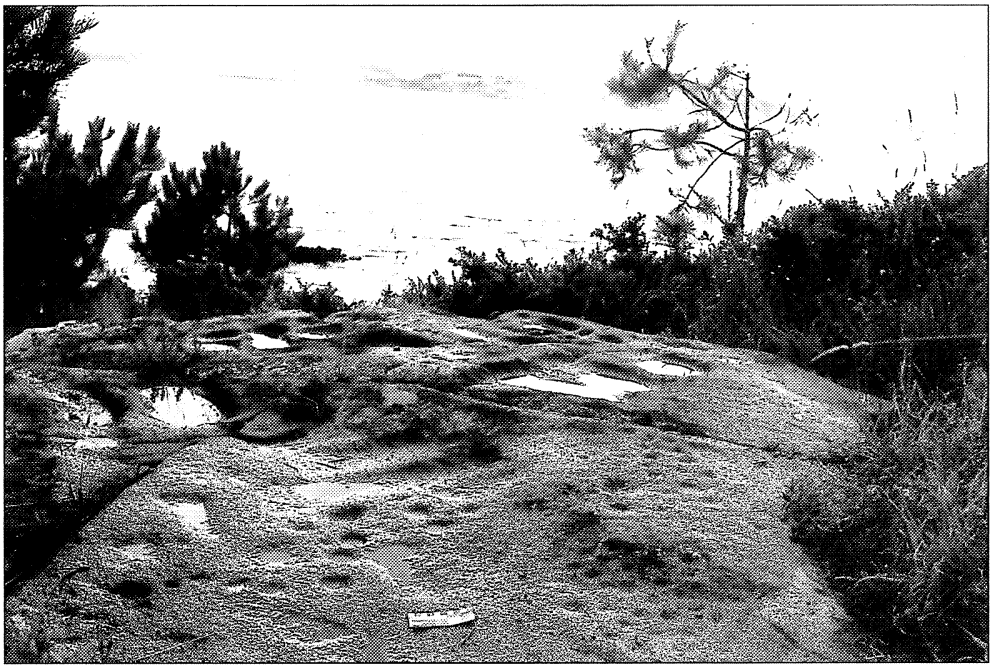

Fig. 2.-Vista desde Monteferro. En primer término roca con piletas y podomorfos, al fondo zona de Bayona. Obsérvese hacia el ángulo inferior izquierdo un podomorfo orientado hacia la bahía.

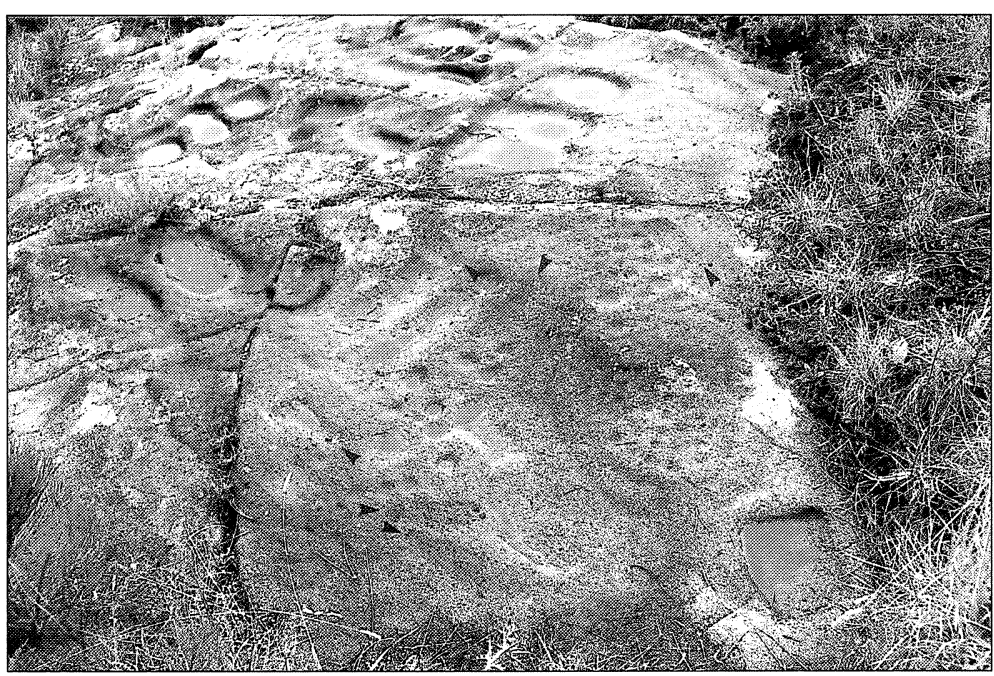

Fig. 3.-Detalle del petroglifo de Monteferro donde se observa los seis podomorfos. Las flechas indican el lugar donde están y su orientación.

\section{Catálogo}

Estudiaremos petroglifos situados en el sudoeste de Galicia. Ello se debe a que es la zona más intensamente prospectada en lo que a arte rupestre se refiere y nos posibilita la valorar la distribución de este tipo de diseño a escala regional (fig. 1).

\section{Monteferro}

Petroglifo inédito, situado la parroquia de Panxón (Nigrán, Pontevedra). Se localiza en el promontorio conocido como Monteferro, que funciona como hito de división, entre las rías de Vigo y Bayona. La roca grabada se localiza en el extremo Sudoeste de dicho promontorio, precisamente en el punto más cercano al islote conocido como Estela de Terra, situado a escasa distancia.

El único yacimiento próximo documentado hasta la fecha es el Castro de Panxón. En las proximidades fue localizada un ara romana dedicada a Mercurio, además hay varios asentamientos de época romana (Costas et al., 1996). Es probable que en la zona de A Medorra, a la entrada del promontorio, existiese un túmulo aludido por el topónimo.

Los grabados se localizan en una de las escasísimas rocas graníticas de la zona. Está forma-

rente. Con esto queremos decir, que la fecha de talla del petroglifo (Edad del Bronce o anterior) no le impide formar parte de un paisaje o ser «usado» en la Edad del Hierro o más tarde. Además no hemos encontrado razones para considerar que las huellas de pie fueran realizadas en épocas más recientes ${ }^{3}$.

\footnotetext{
${ }^{3}$ Existen prácticas «arqueológicas» en sociedades antiguas como el deposito de ofrendas de época oscura, o posteriores, en tumbas de cámara micénicas (Antonaccio, 1995) o la continuidad en el uso de los royal sites irlandeses desde la Edad del Bronce (o antes) hasta la alta Edad Media (Wailes, 1982; Newman, 1997 y 1998; Waddell, 1998, 325-54).
} da por una superficie ligeramente inclinada que ocupa las tres cuartas partes de la roca y una superficie horizontal en la parte superior. En la zona inclinada se encuentran un grupo de molinos rupestres de sección longitudinal navicular unidos por surcos.

En la parte superior horizontal encontramos varias combinaciones circulares formadas por figuras ovales concéntricas abiertas que contienen un grupo de cazoletas; además también encontramos seis rebajes podomorfos con figuración de dedos. Se trata de cuatro pies derechos y dos izquierdos. Los izquierdos se orientan hacia el SSE y NE respectiva- 


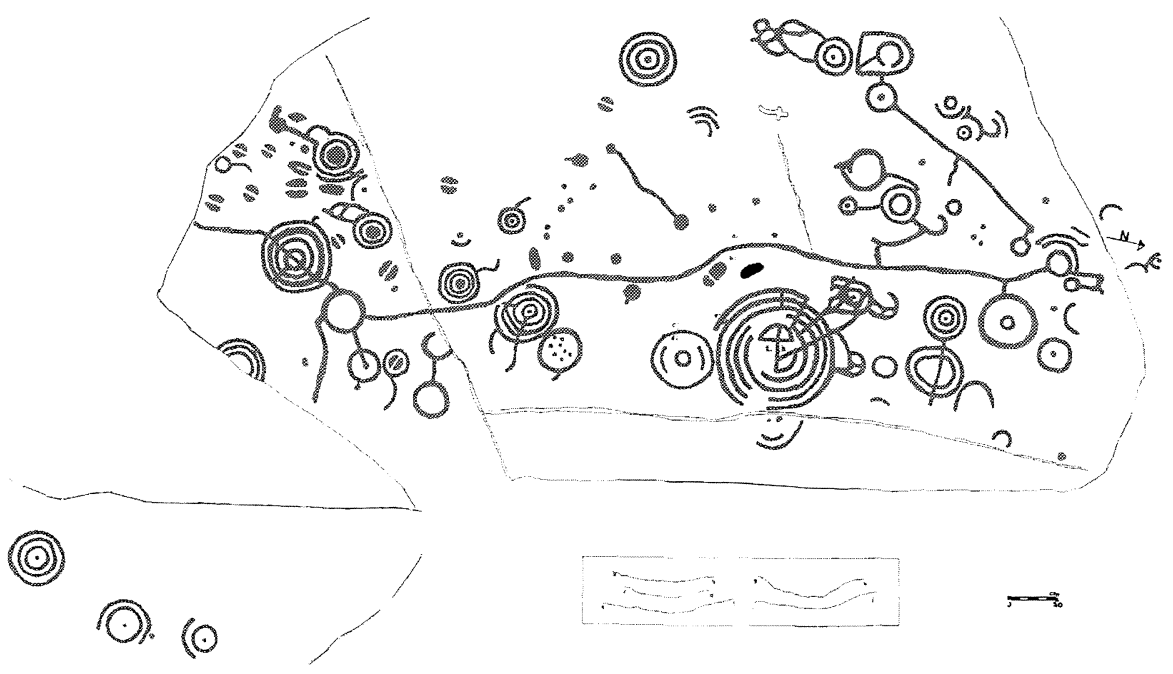

Fig. 4.-Petroglifo de Pedra da Moura según Costas Goberna (1985). En tono más oscuro el grabado podomorfo, que no debe confundirse con el grabado situado a su izquierda, semejante a una suela de zapato.

mente y los derechos al S, SE, O y NO, es decir, que los podomorfos abarcan aproximadamente un arco de unos $270^{\circ}$ desde el Oeste al Sur en el sentido de las agujas del reloj, con lo cual el campo de visión de un individuo con los pies sobre las huellas insculturadas abarca los cuatro puntos cardinales (fig. 3).

El terreno circundante forma una pequeña cuenca que cierra la visibilidad hacia el Oeste y la reduce considerablemente hacia el Norte; en las direcciones Sur y Este el campo de visión se amplía notablemente y es divisable la isla da Estela de Terra (o de Dentro), la villa de Bayona y el valle del Miñor (fig. 2).

En resumen, el emplazamiento del petroglifo está elegido de forma que colocando los pies sobre las huellas inscritas se puede contemplar con naturalidad la Ría de Bayona y las tierras de su entorno más próximo. Además debemos resaltar que los podomorfos se asocian con motivos (combinaciones circulares) pertenecientes, en principio, a la Edad del Bronce, pero el emplazamiento del mismo dista mucho del tipo de emplazamiento más frecuente para grabados de esta época (Santos, 1998, 73-88 y 1996, 13-40). Mientras los petroglifos de la Edad del Bronce se localizan en zonas de entrada a las sierras, en la transición entre el valle y el monte, en ocasiones en torno a zonas húmedas, en el caso de Monteferro el petroglifo se halla lejos de cualquier cubeta o humedal y fuera de toda línea de tránsito significativa a no ser que lo vinculemos con un punto de vadeo para acceder al islote próximo.

\section{Pedra da Moura}

Se localiza en el lugar de Fragoselo (Vigo), al pie de la ladera noororiental de los montes de Coruxo, una de las zonas de mayor concentración de grabados rupestres de la comarca, en su mayoría de la Edad del Bronce. Su emplazamiento no es prominente pero la roca no pasa desapercibida ya que en la zona se estrecha considerablemente la vía de tránsito.

Se trata de una superficie abombada de $10,50 \mathrm{~m}$ de largo por $4,50 \mathrm{~m}$ de ancho que sobresale 0,50 metros. Entre los motivos insculturados predominan las combinaciones circulares, aunque también encontramos cazoletas y huellas de bóvido. Es necesario destacar la presencia de un curioso motivo superpuesto a la combinación circular de mayor tamaño y que consiste en una figura similar a la letra griega «phi», semejantes a los encontramos en el Coto da Cidade en Gargamala, que como su topónimo indica, se encuentra en las inmediaciones de un castro de la Edad del Hierro.

El podomorfo se sitúa en el tercio central / superior de la roca, se trata de un pie izquierdo donde no aparecen representados los dedos; la figura se orienta hacia la zona de más amplia visibilidad. Según los vecinos en la roca hay «pegadas de boi, cabalo e cristiano» (Monteagudo, 1943). La visibilidad desde la roca no es muy amplia debido a la proximidad de montañas y altozanos y a lo angosto de los pequeños valles próximos. Con todo, en la última línea de horizonte son visibles los castros de Monte Alba y Chandebrito (figs. 4 y 5). 


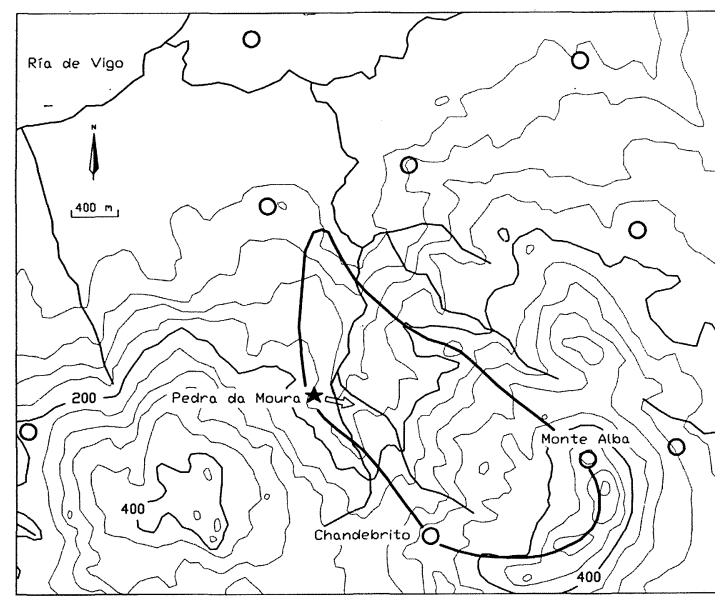

Fig. 5.-Situación de Pedra da Moura y área visible desde el petroglifo. La flecha indica la orientación del podomorfo y los círculos los castros.

\section{Coto San Martiño}

Se sitúa al Sudeste de la provincia de Pontevedra en el valle del Miño en un cerro que sirve de límite entre los ayuntamientos de As Neves y Arbo. El monte de San Martiño forma parte de la estribación meridional del monte de Paradanta. El petroglifo se encuentra en la acrópolis de un castro en una aglomeración rocosa que destaca notablemente en el paisaje (fig. 6). Se trata de un conjunto de diecinueve rocas. Una de ellas, presenta un podomorfo correspondiente a un pie izquierdo orientado hacia el poniente, no aparecen representados los dedos a excepción de una cazoleta que coincide con la posición del pulgar.

En el resto de los paneles de la estación encontramos grabadas cazoletas, piletas de diversas formas y tamaños unidas por surcos, figuras ajedrezadas y serpentiformes. Fuera del castro se sitúa el Chan dos Teceláns, donde se localizan varias rocas con algunos motivos de cronología indeterminada y otros pertenecientes a la Edad del Bronce. Cabe mencionar la existencia, según la tradición, de un monasterio que da nombre al coto, pero en una detallada prospección superficial llevada a cabo en 1986 no se encontraron esos restos (Pérez Paredes y Santos, 1989, 51-80).

Desde el podomorfo se controla visualmente el valle de la parroquia de Sta. María de Sela y parte de S. Juan de Barcela, también es visible la orilla opuesta del río Miño. Si nos situamos en la cima de la aglomeración rocosa la visibilidad abarca, además de la zona antes mencionada, el valle del río Termes destacando en la última línea de horizonte los montes de San Juan y Coto de Sanomedio en el ayuntamiento de As Neves y el cercano Monte do Drago.

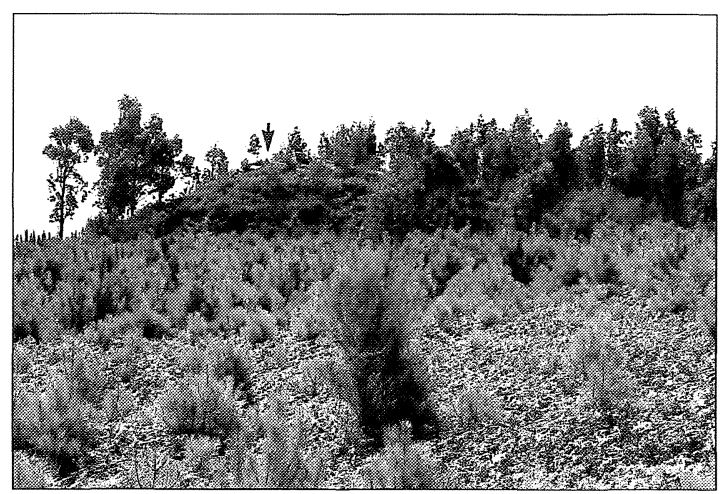

Fig. 6.-Vista de la roca donde está el petroglifo de Castro de San Martiño desde el llano de Chan de Teceláns.

\section{Campo de Matabois}

Se encuentra en el lugar de Caneda (Campo Lameiro, Pontevedra). El petroglifo está en una aglomeración rocosa en un estrecho rellano a media altura de una escarpada ladera, lo cual convierte al lugar en la única zona de paso por esta zona. Contemplada desde el valle, la aglomeración rocosa se recorta perfectamente en el horizonte.

La estación es muy conocida por el gran número de grabados rupestres. Podemos destacar dos grandes grupos de petroglifos. Por un lado, los pertenecientes a la Edad del Bronce: combinaciones circulares, zoomorfos y armas. Por otro, los de cronología indeterminada: cruces inscritas en círculos y cuadrados, herraduras y cazoletas hemicilíndricas. También debemos mencionar que a un kilómetro hacia el Sur se encuentran inscripciones latinas (Santos et al., 1997, 61-80). Los petroglifos pertenecientes a la misma estación poseen todos los motivos específicos del Bronce, como una figura laberintoide, y los que posiblemente pertenecen a la Edad del Hierro presentan un repertorio más reducido en la roca del podomorfo: un posible puñal, cazoletas, improntas de cuadrúpedos (cérvidos o bóvidos), una cruz inscrita en un círculo y una cazoleta hemicilíndrica. El único podomorfo del petroglifo es un pie derecho sin figuración de dedos y orientado hacia el noroeste, dando la espalda, por tanto, al punto de mayor visibilidad, ya que desde la roca es visible la práctica totalidad del valle de Campo Lameiro situado al sudeste (fig. 7).

\section{A Ferradura}

Se localiza en la parroquia de S. Pedro de Trasalba (Amoeiro, Orense), en un llano en altura don- 
de limita con el ayuntamiento de Punxín. El Chan de A Ferradura, topónimo del enclave, está en el extremo sudoccidental del Chao de Amoeiro, constituyendo el límite sudoriental del valle del Barbantiño en la comarca de Maside $^{4}$. La roca que nos ocupa se sitúa en el centro del llano. Los motivos que la decoran son un grupo de «herraduras», una combinación circular, un numeroso grupo de rebajes de sección cilíndrica y cruces, cazoletas y varios grupos de podomorfos (fig. 8). La roca tiene $10 \mathrm{~m}$ de largo por $3,20 \mathrm{~m}$ de ancho y de alto mide $1,50 \mathrm{~m}$. Pese a su tamaño, la roca no destaca sobre el terreno debido al gran volumen de los

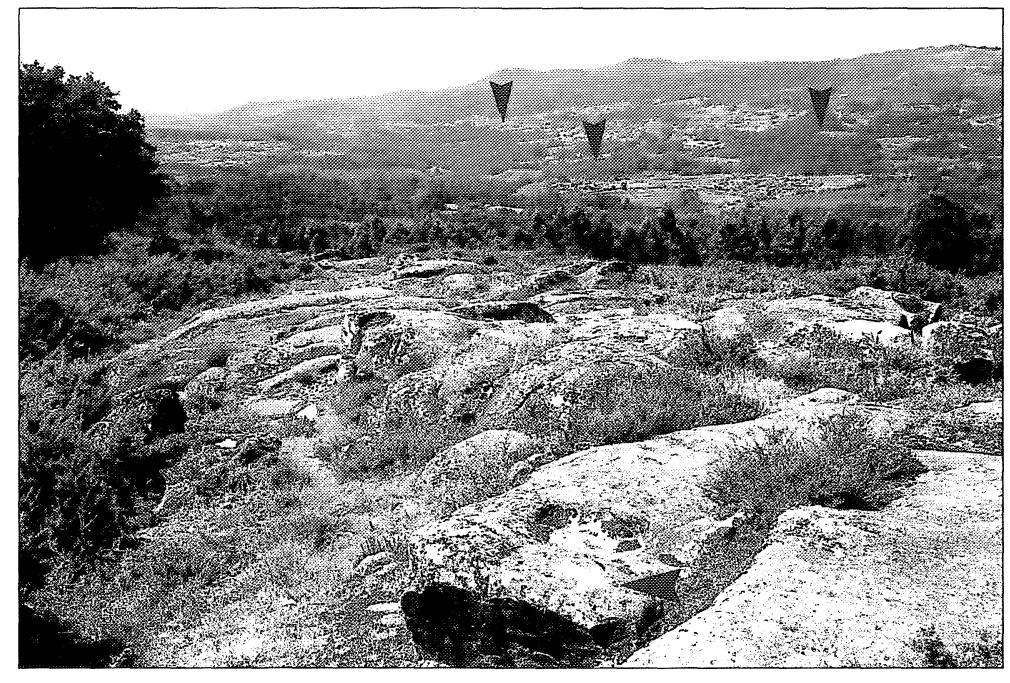

Fig. 7.-Vista desde el Campo de Matabois hacia el valle de Campo Lameiro. La flecha inferior señala el grabado y las restantes los castros visibles desde el petroglifo. muchos afloramientos que ocupan el llano y atenúan su monumentalidad.

El petroglifo se sitúa entre otros muchos, fundamentalmente cazoletas. Hay que hacer la salvedad de dos aglomeraciones rocosas, una con herraduras, reticulados irregulares y cruces inscritas en círculos $\mathrm{y}$ otra formada por un abrigo con una roca exenta y grabada con una figura irregular ${ }^{5}$.

Debemos mencionar también la presencia del Castro de A Zarra en el extremo occidental del llano con dos petroglifos de círculos concéntricos, propios de la Edad del Bronce, y un segundo castro en el extremo Nordeste, Coto do Castro, con un grabado serpentiforme sobre la roca que culmina el enclave y una inscripción de en donde con toda cautela leemos [.]EBA $\{.[\cdot]\} \mathrm{E}$ (fig. 9).

Estamos ante el grupo más numeroso de podomorfos de nuestro estudio. Hay once figuras de pies y otras dos dudosas (fig. 10), distinguimos tres pares de pies izquierdo / derecho, presentando el pie derecho en los tres casos figuración de dedos. Además hay tres pies izquierdos sin pareja, uno de ellos con dedos, y un pie derecho suelto con representación de dedos. Los podomorfos están orientados del siguiente modo: de las tres parejas dos se orientan

\footnotetext{
${ }^{4}$ La estación rupestre de A Ferradura fue descubierta durante el seguimiento arqueológico de las obras de construcción del ramal del gasoducto de Galicia PontevedraOurense. Labores realizadas por Laboratorio de Arqueoloxía das Formas Culturais de la Universidade de Santiago (Amado Reino et al., 1998).

5 Este abrigo con petroglifos presenta una abertura desde la que es visible una estrecha línea de horizonte situada hacia el lugar donde se pone el sol el día del solsticio de invierno.
}

hacia el castro de A Zarra y una tercera hacia el castro de San Trocado. Los cuatro podomorfos izquierdos se orientan del siguiente modo: dos al Norte, uno al Noroeste y otro al Oeste (hacia el castro de A Zarra). El pie derecho se orienta hacia Sudoeste, hacia el gran castro de San Cibrán de Las (fig. 11). Por último las dos representaciones dudosas, posiblemente de pies izquierdos, se orientan hacia Sudeste y hacia el Sur ${ }^{6}$.

\section{SíNTESIS DE LOS DATOS}

Nos centraremos en las características espaciales presentes en cuatro niveles: (1) distribución regional de los grabados; (2) emplazamiento, donde se tendrá en cuenta, entre otros aspectos, la posición en el relieve; (3) situación en la roca y el panel; (4) características formales del grabado.

\section{Distribución regional}

Las estaciones rupestres con podomorfos se localizan en el cuadrante sudoccidental de Galicia. Esta distribución se debe a que es la región donde se ha producido una dinámica de estudio favorable: la detección precoz de grabados rupestres al aire libre impulsó numerosos trabajos de prospección y catalogación y los consiguientes nuevos hallazgos.

${ }^{6}$ López Cuevillas, 1958, 143, da noticia de una romería a la ermita sita en la cima de San Trocado. Sabemos que L. Castro tiene en prensa un libro sobre el folklore de la zona. 


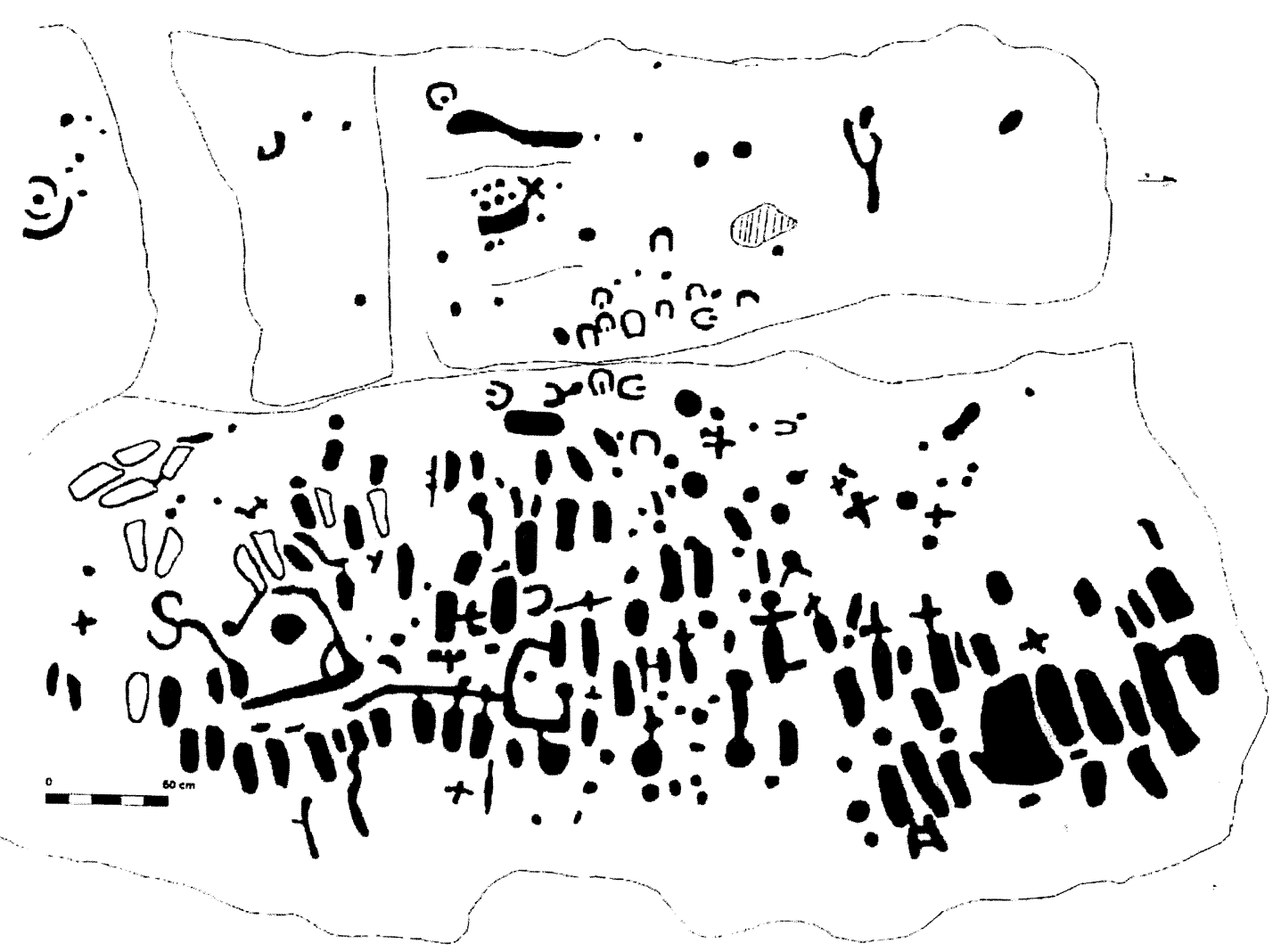

Fig. 8.-Calco de A Ferradura. Los podomorfos se representan con el contorno y sin relleno.

Ello determina que los podomorfos documentados hasta la fecha se sitúen en esta zona. Pero no creemos que estemos ante un motivo zonal, consideramos que futuras prospecciones en otras áreas revelarán más figuras de este tipo.

Otro elemento a tener en cuenta es la distribución regular de los motivos, aunque insistimos en que nuestro conocimiento sobre la distribución real de los podomorfos dista de ser completa. Hay que señalar que mientras muchos de los motivos minoritarios parecen poseer una distribución local (ídolos, paletas), los podomorfos, se localizan de forma regular, y nunca aparece más de una roca con huellas de pie en la misma estación o incluso en la misma unidad de relieve.

\section{Emplazamiento}

La ubicación en el paisaje de un yacimiento determina un aspecto fundamental: sus condiciones de visibilidad. A larga distancia no se puede considerar la visibilidad de la roca, pero cabe identificar algún elemento orográfico próximo, discernible desde la lejanía, que permita establecer un vínculo intuitivo entre dicho «monumento salvaje» en expresión de Criado $(1993 b, 48)$ y el artificial o petroglifo.

Esta consideración es pertinente pues de nuestros cinco casos sólo uno aparece en un lugar discreto en el paisaje, Pedra da Moura. El de Monte-

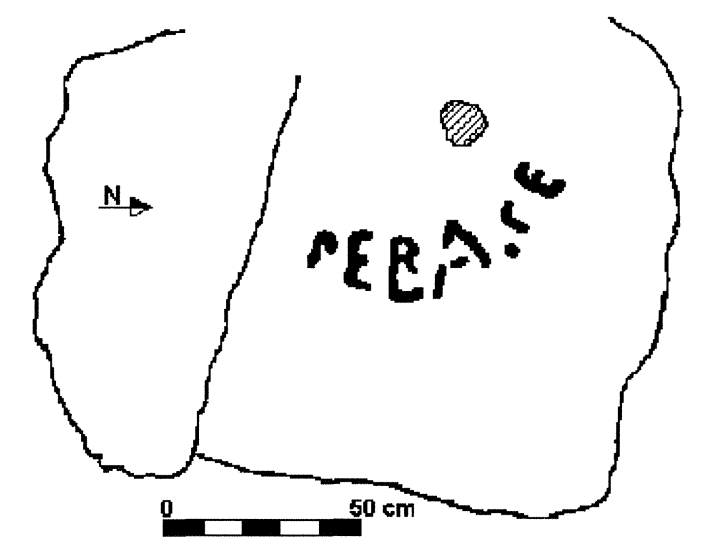

Fig. 9.-Inscripción sobre una roca horizontal situada muy cerca de la cima del Coto do Castro y a unos trescientos metros del petroglifo de A Ferradura. 
ferro también, aunque en este caso el petroglifo está en un monte que destaca notablemente. Los tres restantes, que no se vinculan directamente con grabados de la Edad del Bronce, se sitúan en puntos destacados: cima de un monte (San Marti$\tilde{n} o)$, aglomeración rocosa $(M a-$ tabois) o rodeado de grandes batolitos y cerros pedregosos $(A$ Ferradura).

En cualquier caso todos los petroglifos tienen en común que su dominio visual sobre el entorno, aunque amplio, apenas desborda el valle en el que se encuentran. Ello se debe a que el emplazamiento de estas rocas no

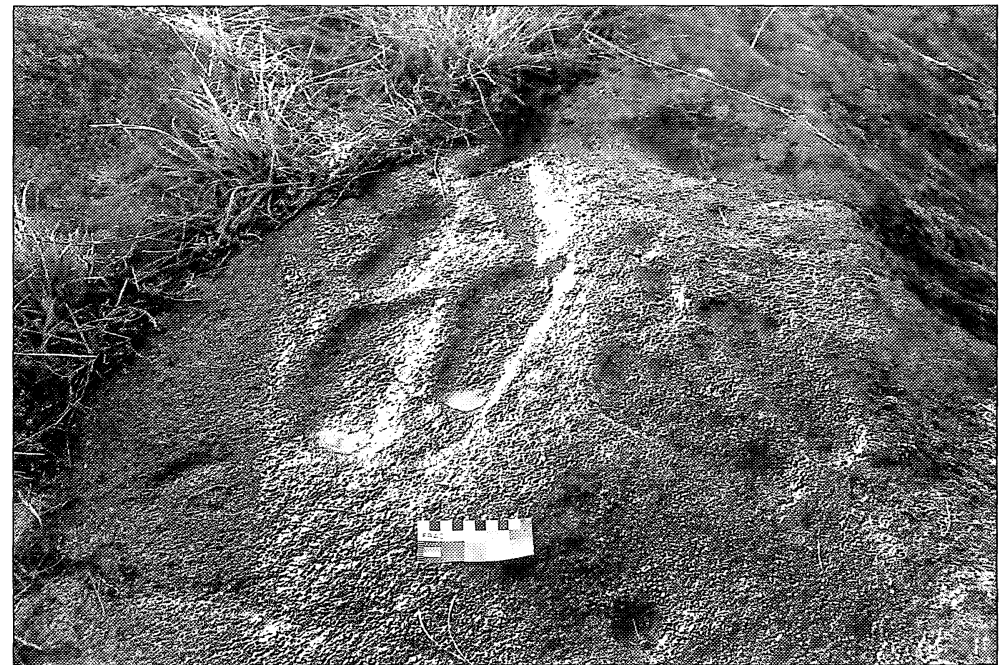

Fig. 10.-Detalle de un grupo de podomorfos de A Ferradura. se localiza en la divisoria de aguas de las sierras, sino en los bordes visuales contemplados desde el valle. Resumiendo, podríamos definir la visibilidad de los podomorfos como un arco que incluye un único valle de tamaño medio, situado en un lugar fácilmente identificable desde las tierras bajas y apartado del espacio doméstico o de frontera tal y como es caracterizado por Parcero $(1995,127-44)$.

\section{Contexto arqueológico}

Lo más destacable respecto a los restos arqueológicos asociados a los podomorfos es la existencia de dos grupos bien diferenciados. El primer grupo está formado por los petroglifos de Monteferro y Pedra da Moura. En ambos las rocas aparecen aisladas y los únicos elementos asociables son aquellos con los que comparten panel, combinaciones circulares de la Edad del Bronce.

El segundo grupo está formado por los podomorfos asociados a motivos de cronología indeterminada (cazoletas convencionales o hemiesféricas, cazoletas hemicilíndricas surcos ondulantes y cruces inscritas), motivos de la Edad del Bronce y asentamientos de la Edad del Hierro (San Martiño, A Ferradura y Campo de Matabois). El caso más claro de asociación entre castro y podomorfo lo tenemos en San Martiño, donde el grabado se sitúa en la cima de un castro. Pero quizás más llamativo resulte el caso de $A$ Ferradura, superficie compuesta por un total de 11 podomorfos de los cuales 6 están orientados hacia alguno de los castros de la zona.

\section{El soporte y su situación}

Los cinco petroglifos analizados se encuentran en rocas graníticas de tamaño variado. Una característica común es que las rocas que tienen podomorfos se sitúan en peñas que sobresalen, en contraste con la mayoría de los petroglifos gallegos grabados en rocas a ras del suelo o poco destacadas sobre el terreno. En el caso de la Pedra da Moura se trata de una gran piedra de perfil abombado que levanta al menos medio metro, San Martiño se encuentra en una destacada aglomeración rocosa, en Matabois el podomorfo está en la roca más alta de la estación sobresaliendo alrededor de un metro, la roca de $A$ Ferradura alcanza 1,40 metros de alto. En Monteferro está la única roca a ras del suelo, pero aquí el soporte se halla en una ruptura de pendiente que le permite destacar sobre el entorno, además se escogió una roca granítica en un paraje donde no abunda. En todos los casos estudiados los podomorfos están en superficies horizontales y con clara tendencia a buscar los lugares más altos del soporte. Esto, sin duda, facilita su uso en la forma que expondremos más adelante.

\section{El panel}

La variedad de motivos que comparten panel o que se encuentran en superficies inmediatas es bastante limitada: combinaciones circulares, un puñal, molinos rupestres, piletas con surcos de desagüe, improntas de cuadrúpedos, cruces simples, una cruz inscrita, cazoletas hemicilíndricas, diseños en «phi» 


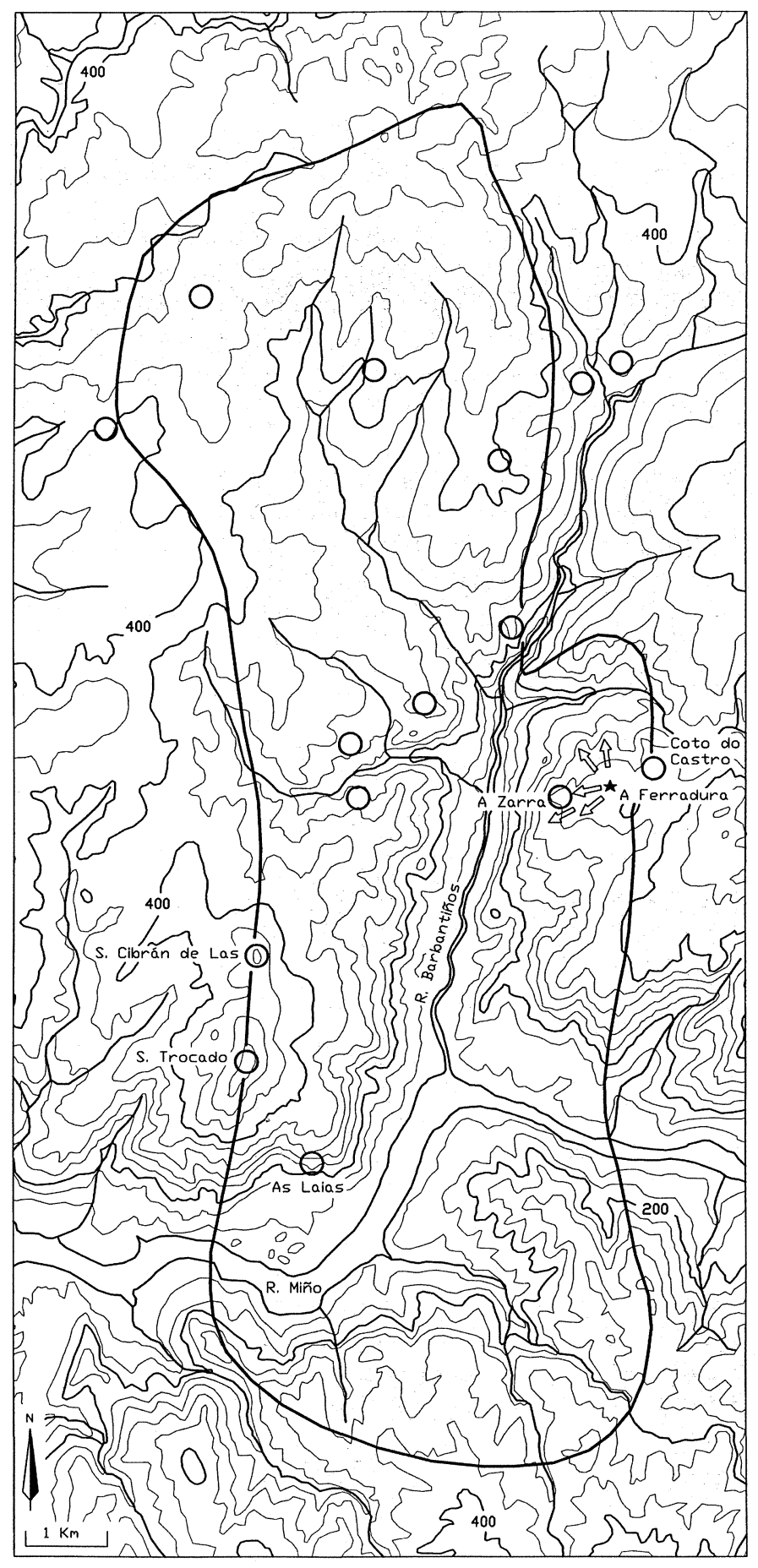

Fig. 11.-Situación de A Ferradura y área visible desde el petroglifo. Las flechas indican la orientación de los podomorfos y los círculos los castros.

y surcos ondulados y serpentiformes. Quizás lo más llamativo sea la presencia de seis tipos de motivos que son escasos en el conjunto del arte rupestre ga- llego, pero que en cambio se repiten en las estaciones con podomorfos, éstos son las cazoletas hemicilíndricas que aparecen en las estaciones de Castro de San Martiño, Matabois y A Ferradura; las improntas de cuadrúpedos en Matabois y Pedra da Moura; las herraduras en Matabois y A Ferradura; los serpentiformes y surcos ondulantes en Pedra da Moura y San Martiño y las piletas y molinos con desagües en Monteferro, San Martiño y $A$ Ferradura. Como contraste, llama la atención la escasa presencia de motivos mayoritarios en otros contextos como son las combinaciones circulares o los zoomorfos.

Podemos resumir resaltando la reiteración de dos grupos de motivos: las piletas o molinos rupestres con desagües y las cazoletas hemicilíndricas. El primer grupo de grabados sugiere la idea de haber sido utilizados para derramar algún líquido, esta posibilidad parece bastante clara en Monteferro y San Martiño y más improbable en A Ferradura debido a la excesiva inclinación de la roca. El segundo grupo es el de las cazoletas hemicilíndricas que en cierto modo no dejan de ser pequeños recipientes, la mayoría en torno a $20 \mathrm{~cm}$ de largo y $8 \mathrm{~cm}$ y que al igual que los podomorfos, tienden a situarse en superficies elevadas y horizontales.

\section{Los podomorfos}

Estamos ante una muestra de 19 podomorfos que reúnen las condiciones requeridas para ser considerados como tales. Destaca el predominio de pies izquierdos (12 frente a 7 derechos). En raras ocasiones forman parejas complementarias, es decir grupos de dos podomorfos uno izquierdo y otro derecho. Tres de las cinco rocas sólo presentan un pie. En Monteferro encontramos cuatro pies derechos y dos izquierdos que no forman pareja, a no ser que reflejen una postura inverosímil. En A Ferradura localizamos al menos tres parejas de podomorfos complementarias y compatibles, con la particularidad de que en los tres casos solamente el derecho tiene dedos, dando a entender que uno de los pies está calzado mientras que el otro aparece desnudo. 
Con respecto a la orientación de los motivos grabados tenemos datos significativos. En Monteferro los seis podomorfos están orientados de forma radial abarcando visualmente la casi totalidad del espacio circundante. En el caso de A Ferradura de los once pediformes nueve se orientan hacia algún castro de la zona como ya apuntamos; tanto en el caso de San Martiño como en el de Pedra da Moura las figuras no se orientan aparentemente hacia ningún lugar puntual aunque sí lo hacen hacia el lugar de mayor visibilidad sobre el valle. En cambio, el pie de Campo de Matabois da la espalda al valle orientándose hacia un pequeño rellano próximo.

\section{Planteamiento general sobre los PODOMORfoS}

A pesar de la corta muestra es posible extraer conclusiones sobre las características de los petroglifos con podomorfos:

1. Se emplazan un lugar elevado con respecto al valle, en rocas desde la que se divisa una amplia panorámica.

2. La roca que sirve de soporte al petroglifo se eleva ligeramente sobre el entorno más inmediato y los podomorfos se ubican en su superficie más horizontal y elevada.

3. Los motivos con los que suelen compartir panel son piletas con canales de desagüe, cazoletas hemicilíndricas, herraduras e improntas de cuadrúpedos.

4. Predominan los pies izquierdos sobre los derechos. En las raras ocasiones que forman parejas complementarias uno de los pies se representa descalzo.

5. En ocasiones los podomorfos parecen estar orientados hacia puntos determinados, hacia los cuatro puntos cardinales o hacia castros cercanos.

6. Distinguimos dos grupos bien diferenciados. Los podomorfos situados en lugares más discretos del paisaje, asociados a petroglifos de la Edad del Bronce, y los podomorfos situados en lugares destacados, en contextos de la Edad del Hierro.

\section{ELEMENTOS COMPARATIVOS}

RITOS ESCOCESES E IRLANDESES

La lectura casual de un texto procedente de Escocia, país céltico goidélico (i.e. irlandés), relativo a la investidura de un «Señor de las Islas», nos puso sobre la pista del posible sentido de nuestros petroglifos podomorfos. Pues en él se describe una acción concreta efectuada sobre un grabado de este tipo.

«...I thought fit to annex the ceremony of proclaiming the Lord of the Isles. At this the bishop of Argyle, the Bishop of the Isles and seven priests, were sometimes present; but a bishop was always present, with the chieftains of all the principal families, and a Ruler of the Isles. There was a square stone, seven or eight feet long, and the tract of a man's foot cut thereon, upon which he stood, denoting that he should walk in the footsteps and uprightness of his predecessors, and that he was installed by right in his possessions. He was clothed in a white habit, to show his innocence and integrity of heart, that he would be a light to his people, and maintain the true religion. The white apparel did afterwards belong to the poet by right. Then he was to receive a white rod in his hand, intimating that he had power to rule, not with tyranny and partiality, but with discretion and sincerity...» ${ }^{7}$.

Esta noticia se completa con otra menos detallada pero que corrobora la utilización de la piedra con el podomorfo. En una isla del Loch Finlagan, en Islay, Escocia, en donde recibían su investidura los Macdonalds de las Islas:

«There was a big stone of seven feet square, in which there was a deep impression made to receive the feet [sic] of Macdonald; for he was crowned King of the Isles standing in this stone...» ${ }^{8}$.

Testimonios procedentes de Irlanda confirman de diferentes formas la utilización de podomorfos tallados en roca en los ritos de investidura céltica. En efecto, Spenser describe a fines del siglo XVI el rito de investidura de un Captaine irlandés en su View of the state of Ireland:

«It is a custome amongst all the Irish, that presently after the death of any of their chiefe Lords or Captaines,

7 Mac Cana, 1968, 180, texto tomado de Higland papers, ed. J.R.N. Macphail, pp. 23-4, Scottish Historical Society, 2nd series, vol. 5, 1914.

${ }^{8}$ Mac Cana, 1973, 162, cita M. Martin, A Description of the Western Islands of Scotland, Stirling, 1934, 273. Sobre esta piedra Hayes-McCoy, 1970, 93n26, cita Clan Donald Magazine, no. 3, 1965, pp. 5 ss. e informa de su destrucción por los ingleses en 1615. En la fortaleza de Cickhimin, Shetland había un bloque de piedra grabado con el perfil de dos pies situado a las puertas del recinto amurallado (Harmand, 1970, 48). La versión cinematográfica de Macbeth dirigida por Roman Polanski en 1971 presenta la escena de investidura con el rey en pie sobre una roca tallada con podomorfos. Shakespeare no ofrece detalles Macbeth, Acto II, Escena IV, 31-2, habla Macduff: «He [Macbeth] is already nam'd, and gone to Scone to be invested»; Muir, 1977, ad loc., tampoco da mayores precisiones. Sobre la accidentada historia y leyenda de la Stone of Destinity de Scone, sobre la que se coronaban los reyes de Escocia véase Gerber, 1997, quien señala (pp. 23-5 y 63-4) cómo en Escocia los petroglifos podomorfos se interpretan obviamente como lugares de investidura real. Boswell, 1974, 319, en la crónica de su viaje a Escocia en 1773, indica que el monte Scone y otros se llamaban laws pues en ellos se administraba justicia antaño y en su época servían de residencia a los sheriff. 
they doe presently assemble themselves to a place generally appointed and knowne unto them to choose another in his steed... [siguen indicaciones sobre los elegibles]... They use to place him that shalbe their Captaine, upon a stone always reserved for that purpose, and placed commonly upon a hill: In some of which I have seen formed and engraved a foot, which they say was the measure of their first Captaines foot, whereon he standing, receives an oath to preserve all the auncient former customes of the countrey inviolable, and to deliver up the succession peaceably to his Tanist [segundo en la realeza y heredero], and then hath a wand delivered unto him by some whose proper office that is; after which, descending from the stone, he turneth himselfe round, thrice forward, and thrice backward. But how is the Tanist chosen? They say he steth but une foot upon the stone... (citado por McCana, 1973, 162, y Byrne, 1973, 38)

También en Irlanda la investidura de los O’Neill maneja de forma autónoma los símbolos que ya conocemos. El rito y el escenario están representados por cartógrafos y dibujantes del siglo XVI, cuando la ceremonia todaría se desarrollaba según el antiguo uso. El futuro Earl of Tyrone, autoproclamado descendiente de los reyes del Ulster, subía a una colina llamada Tullaghoge cerca de Armagh; allí se sentaba en una roca con forma de silla (destruida por los ingleses en 1602) y uno de los participantes sostenía un zapato sobre su cabeza, gesto con el que se simbolizaba que el nuevo O'Neill seguiría las huellas de sus antecesores, que se remontan hasta el siglo XI. Según otras versiones de la ceremonia, el zapato se arrojaba sobre la cabeza del investido. Además el rey efectuaba un baño ceremonial y recibía un bastón ${ }^{9}$.

Las ideas que hemos subrayado en el texto que nos ha servido de referencia: and the tract of $a$ man's foot cut thereon, upon which he stood, denoting that he should walk in the footsteps and uprightness of his predecessors, reaparecen en el relato mítico irlandés sobre la piedra de Fal. Se trata del episodio que relata el ascenso a la realeza de Conn, ejemplo de buen rey de Irlanda:

«Un día, Conn estaba en Tara tras la destrucción de los reyes. Va muy temprano a la fortaleza real de Tara antes de la salida del sol; sus tres druidas estaban con él... En el lugar al que iba siempre, encuentra una piedra bajo su pie que se escuchó en toda Tara y en todo Brega... [el druida le explica] 'Fal es el nombre de la piedra.

9 Hayes-McCoy, 1970. El lugar no parece haber dejado rastro en el folklore, pues ninguna de las fiestas en altura registradas en el condado de Tyrone se refiere a este emplazamiento. En una de ellas, Altadavin, MacNeill, 1962, 152-5, menciona una Silla de San Patricio y cazoletas utilizadas por los asistentes a la romería del Domingo después del 26 de Agosto. En el libro de MacNeill se presentan otros casos de colinas de investidura, con o sin podomorfos humanos y / o animales, listados en los índices de la obra. Estos lugares de investidura no deben confundirse con los royal sites (supra n. 3). En Irlanda hay otros ritos de investidura sin relación con nuestro tema (Le Roux, 1963; Pontfarcy, 1987).
Se trajo de la isla de Fal. Es en Tara en la tierra de Fal que se levantó. Permanecerá para siempre en la tierra de Tailtiu y es.sobre esta tierra que tendrá lugar la asamblea de los juegos en tanto que subsista la soberanía de Tara Y el último día de la asamblea, si un príncipe no da testimonio, el año será malo. Fal gritó bajo tus pies... y ha profetizado. El número de gritos que ha dado la piedra es el número de reyes que saldrán de tu familia para siempre. No seré yo quien te los nombrará» ${ }^{10}$.

En ambos textos se insiste en la relación piedrasoberanía y, más en concreto, piedra como símbolo de la continuidad de la realeza en forma genérica (primer texto) o dinástica (segundo texto, idea también presente en la ceremonia de Armagh).

La simbología de los podomorfos irlandeses se caracteriza, además, por su persistencia en el folklore de la isla. MacNeill $(1962,113)$ recoge el folklore del condado de Sligo, señalando, entre otras cosas, la existencia de una laja a orillas de un acantilado, con marcas de pezuña hechas por el caballo blanco del señor de Tireragh, y un fuerte en donde se ven dos huellas de pie que conservan un verde eterno y sobre las que, según se cuenta, se coronaba al rey.

No se nos escapa que el tema icónico descrito está presente en el repertorio de petroglifos de todo el occidente atlántico ${ }^{11} \mathrm{y}$ que representaciones de pies sobre distintos soportes se conocen en el Sahara Occidental (Pellicer et al., 1973-1974, 20-1, 43-4 y figs. 27c y 29b), en Egipto desde su prehistoria hasta el Islam (Castiglioni, 1970), también hay testimonios en la India y el mundo oriental helenístico y romano (Castiglioni, 1971; Guarducci, 19421943) y probablemente en estas últimas categorías más cercanas al mundo clásico deban integrarse dos testimonios procedentes de Galia (Lejeune, 1985 , G112 y G152). Dentro de la Península Ibérica están atestiguados, además de los que nos ocupan, en monumentos rupestres de Tarragona y Murcia y otros más dentro de los motivos decorativos de epígrafes (Vilaseca, 1943, 254-7; Molina, 1989-1990; Erkoreka, 1995; Rodríguez Colmenero, 1999, 1145 , recoge otra bibliografía).

No creemos posible una interpretación homogénea de todos estos testimonios. En cada caso con-

${ }^{10}$ Citado por Le Roux y Guyonvarc'h, 1995, 146-147; Guyonvarc'h, 1967, 217, reúne textos que corroboran la idea de que la piedra representa la continuidad dinástica al situar en una roca especial el nacimiento del heredero real. Véase Loth, 1917; esta corriente de estudios, que prolongamos en estas páginas, procede de Loth, 1915.

11 Dumézil, 1993, 44-46; Saxo Gramático, Gesta Danorum, I, 2, 1, transmite un uso que invierte lo visto hasta ahora: «Nuestros antepasados, cuando tenían que elegir a un rey, acostumbraban a proclamar el resultado del voto en pie sobre piedras fijadas en el suelo, pensando que la solidez de las rocas bajo sus pies presagiaba la duración de la elección». 
viene acudir a las fuentes de índole diversa que registran el simbolismo del pie con un amplio abanico de posibilidades que van desde la simbología sexual, a la funeraria, la riqueza, la magia, la relación con la tierra, los ritos de fundación, etc.

En nuestro caso la similitud entre las descripciones de las rocas donde celebran sus investiduras los señores escoceses o irlandeses y la realidad material de las rocas donde aparecen los podomorfos galaicos, que se resumen en la tabla adjunta, nos invitan ya a profundizar en esta línea.

\begin{tabular}{|c|c|}
\hline Escocia/Irlanda, testimonios literarios & Galicia, descripción arqueológica \\
\hline $\begin{array}{c}\text { roca cuadrada, } 7 \text { u } 8 \text { pies largo, } \\
7 \text { pies cuadrados }\end{array}$ & Rocas destacadas. Tamaño variable \\
\hline situadas en alturas & $\begin{array}{c}\text { situadas en alto, o con visibilidad } \\
\text { determinada }\end{array}$ \\
\hline $\begin{array}{c}\text { huella de pie sobre la que se coloca } \\
\text { el rey }\end{array}$ & $\begin{array}{c}\text { huellas de pies con otros } \\
\text { petroglifos }\end{array}$ \\
\hline
\end{tabular}

\section{RITOS VIZCAINO Y CARINTIO}

Para seguir nuestro argumento, conviene centrarnos en una situación análoga a la que nos sirvió de punto de partida y nos previene contra el riesgo de tomar la parte por el todo. Se trata de un pasaje que el cronista Alfonso de Palencia inserta en su evocación de la rivalidad entre los condes de Haro y de Treviño en donde escribe lo siguiente:

«Así cuando el [rey] de Castilla, de quien los vizcaínos se confiesan vasallos, visita su provincia, disponen aquellas [las 'disposiciones' previstas en las leyes del país] que vaya a la villa de Guernica a pie, descalzo del izquierdo, vestido con sencillo jubón y rústico sayo, llevando en la diestra un ligero venablo, y que al aproximarse a la vieja encina que en el valle cercano a la población levanta sus robustas ramas, corra hacia ella en presencia de los vizcaínos que le acompañan y lance el arma contra el tronco para después arrancarla con la mano. Hecho esto, jura el Rey observar las antiguas instituciones de los pueblos, no ir en nada contra sus libertades y mantenerlos exentos de todo tributo...» (citado por Delpech, 1997, 66)

Desde el punto de vista del método destaca que un detalle ritual aislado, todo evocador que se quiera, nunca puede tomarse por el todo. Si el petroglifo de un pie no puede ser testimonio de un «culto a las rocas», como se aprecia en la lectura de los paralelos irlandeses, el monosandalismo del señor de Vizcaya no puede indicar ni el origen pelasgo de la costumbre, ni la pobreza de los señores del país ${ }^{12}$. Sólo la

12 Argumentos respectivos de Andrés de Poza y de Gabriel de Henao, entre otros eruditos recogidos por Delpech, 1997, que se centra en el estudio del monosandalismo. consideración global del rito ayuda a comprender los distintos gestos en los que se descompone.

Pero en este caso vasco no hay piedra, aunque hay encina. Esto nos devuelve al texto de Martín de Dumio, donde habla del culto supersticioso a piedras y árboles de los rústicos de su tiempo. Esa presunta «dendrolatría» no era más que la parte de un todo, y su mención tiene la misma pertinencia que la evocación del monosandalismo del rey por parte de Andrés de Poza, pues con la misma hubiera podido describir el gesto del rey ante el árbol como elemento clave, teniendo esa hipotética referencia el mismo sentido que el gesto que describe efectivamente, de tomar la parte por el todo y excluir la consideración de un rito complejo.

En Galicia no tenemos árboles equivalentes al de Guernica, o con la durabilidad en la memoria de los petroglifos isleños citados. Aunque en el mundo céltico están bien atestiguadas las reuniones o asambleas en bosques y el lugar destacado del roble o la encina en ellas (García Quintela, 1999, 147-156), situaciones cuyos paralelos en el Noroeste peninsular lo constituyen topónimos como Nemetobriga o Nemeño (castro de la comarca de Bergantiños, La Coruña) o el apelativo Nemedeco del dios indígena Coso en Paços de Ferreira ${ }^{13}$.

Volviendo a nuestra podología, destaca el caso vizcaíno doblemente por su similitud y diferencia con lo visto hasta ahora. Las rocas talladas en el arte rupestre y la postura del rey investido sobre podomorfos relatadas para Irlanda, evocan una postura estática, como las propias piedras. Mientras que en el Vizcaya el rey va descalzo del izquierdo y ante la encina de Guernica corre para lanzar su venablo contra ella.

Se trata, pues, de dos maneras muy distintas de subrayar el papel del pie en los ritos de investidura. Esto se aprecia en una serie de situaciones paralelas reconocidas a lo largo del mundo indoeuropeo ${ }^{14}$. De entre ellas podemos destacar una cuya similitud con el rito vasco ha estudiado Delpech. Se trata de la ceremonia de investidura de los duques de Carintia descrita por Eneas Silvio Piccolomini (1998, 108-11), humanista y futuro papa Pío II, que se celebró por última vez en 1414.

13 Búa, 1999, 314-7, Marco Simón, 1993. Vadé, 1977, pone de relieve la similitud entre la simbología de ciertos árboles y rocas, pero el folklore arbóreo galaico no parece ir por ese camino, ni por el de los árboles jurídico-políticos vascos, a tenor de los materiales reunidos por Taboada, 1957. Sobre nemeton, Le Roux, y Guyonvarc'h, 1986, 228-31.

${ }_{14}$ Dubuisson, 1978b; Briquel, 1983. El dossier podría incrementarse con casos griegos. Vernant, 1982, ha estudiado la relación entre forma de marcha y soberanía en el mito de Edipo y su familia de labdácidas, «cojos». Véase más bibliografía en Delpech, 1997. 
La ceremonia se desarrollaba en torno a un trozo de columna procedente de la cercana ciudad romana, y antes céltica, de Virunium, situada en una pradera. Un campesino se sentaba sobre la piedra rodeado por campesinos de la región. Entonces llegaba el duque vestido de campesino, con calzado rústico y un cayado en la mano, acompañado de nobles vestidos de púrpura y con estandartes. Tenía lugar un intercambio de palabras entre el campesino sobre la columna y el duque, que se comprometía a ser juez justo, dador de riqueza y defensor muy cristiano. Seguidamente el duque simulaba la compra la piedra sobre la que se instalaba. Desde allí blandía una espada desnuda en todas las direcciones, jurando que sería buen juez. Para terminar se dirigía a la iglesia cercana en donde asistía a la misa y ya vestido con su traje ducal presidía un banquete y regresaba a la pradera para impartir justicia.

De esta forma ha desaparecido la encina pero hemos vuelto a la piedra, al tiempo que el tema del calzado y los pies queda muy desdibujado tras la mención de la rusticidad del calzado en la vestidura que lleva el duque en la primera parte del rito.

\section{ELEMENTOS DE FOLKLORE FRANCÉS DE ÉPOCA MODERNA}

Algunos usos folklóricos confirman la importancia del rito efectuado sobre la piedra y en concreto de la correcta ubicación de los pies sobre ella por parte del jefe que entra en funciones. En 1926 Loth recogía una noticia publicada en 1768 según la cual:

«Lors de l'installation d'un nouveau maire à Brest, au XVIIIe siècle, après la cérémonie à l'église, l'élu devait se rendre auprès d'une pierre ronde percée au milieu, qui était censée être le centre de la ville, mettre le talon dans le trou et faire le serment de se bien comporter dans ses nouvelles fonctions» ${ }^{15}$.

Un sentido y carácter muy semejante tiene la toma de posesión del llamado Mouistre, «Amo», de

15 Loth, 1926, cita una Guide des chemins de France, 1768 , y da por perdido el monumento. A este contexto pertenece la noticia sobre una pierre du milieu du monde o la limite du baron ou du pays en el municipio de Amancy en Alta Saboya, que Deonna, 1926, identifica como un onphalos céltico. P.-Y. Sébillot, 1950, 116-7, recoge en Bretaña bajo el epígrafe «pierres municipales et de justice» noticias semejantes a las vistas. Son menos significativas en el conjunto de Francia, P. Sébillot, 1983, 138-246. L. PlanchaisLagatu, vecino de Brest y editor especializado en temas célticos, nos comunica la existencia de tradiciones locales sobre el denominado «roi de Brest». Muchas piedras de justicia bretonas se destruyeron durante la revolución. Los ingleses también destruían las piedras de investidura escocesas e irlandesas. una comunidad campesina de Auvernia, también en el siglo XVIII, aunque de nuevo pasamos de la piedra al árbol como lugar central de la ceremonia, este Amo:

«... era el único que tenía derecho a llevar zapatos; los parcioneros llevaban zuecos y los niños iban descalzos... Lo elegían en la familia principal y casi siempre por derecho de primogenitura. Sin embargo, esta no era más que una designación tradicional que podía no ser ratificada por la asamblea... Los Pinon de Auvernia celebraban la elección bajo una gran encina, de varios siglos, en medio de una vasta pradera separada del camino de explotación por una hilera de colmenas, más allá del cual se hallaban los talleres profesionales. Desde allí se descubren hacia el día (Oriente) las montañas de Forez; al mediodía (Sur), la Limagne, cuyos campos y praderas se mezclan con los viñedos; hacia la noche (Occidente), las cúpulas redondeadas del macizo de Auvernia; al cierzo (Norte), en forma de anfiteatro, el bosque de Saint-Remy. La elección se hacía solemnemente sin ruido, habiéndose consultado ya a los parcioneros... El nuevo Amo prometía cumplir fielmente su deber, luego les contaba lo que sabía de la historia de la gran familia y les hablaba de las modificaciones que creía útiles...» (Funck-Brentano, 1953, 55-60).

En este caso el tema del calzado, presente, aparece desplazado de la ceremonia, pero llama la atención la designación de los puntos cardinales que suponen una auténtica apropiación del espacio, no sólo por su orientación sino también por la diversificación de su explotación económica: montaña (¿pastoreo?), tierras de cultivo y bosques para la recolección. Que, una vez más, estamos ante un rito de soberanía, mantenido en este caso por la tradición en la esfera de la jefatura de una comunidad campesina, queda atestiguado por el paralelo exacto que proporciona uno de los múltiples ritos en los que se descompone el rajasuya, antiguo rito indio de consagración real. Se trata del digvyasthapanam o «ascenso de los cuartos del espacio»:

«Cuando el sacrificante [rey en cuyo beneficio se celebra toda la ceremonia] ha sido vestido y equipado para la ceremonia de unción, el adhvaryu [sacerdote] le dice que ascienda los cuartos del espacio mediante un paso dado en cada una de las cinco direcciones. El adhvaryu informa al sacrificante en cada ocasión sobre la fórmula que debe proferir en cada ocasión en la que se asocia la dirección pertinente con una serie de entidades relativas al sacrificio o al cosmos» (Heesterman, 1957, 103).

Los cinco puntos indicados son los cuatro cardinales con el central o zénit. En este caso las divisiones del espacio (puntos cardinales) y del tiempo (estaciones) se agrupan con los poderes del sacrificio y las fuerzas que conforman el orden social y cósmico (brahman, ksatra, vis con auxilio de balam, Heesterman, 1957, 104; cf. Rees, 1961, 118-139, para Irlanda). En esta concepción el quinto paso relativo al 
zénit destaca como más alto así, al dar ese quinto paso, el sacrificador (= rey) se apropia de la totalidad del universo (Heesterman, 1957, 104, 196-9).

Citemos, por último, un monumento sito en el antiguo territorio de los secuanos, sobre la colina de la Belle-Perche en Bleurville, Vosgos. Es un yacimiento complejo, con superposición de restos de épocas diversas con una serie de rocas naturales esculpidas con distintos motivos. La que nos interesa presenta dos podomorfos, uno orientado hacia el Sur y otro hacia el Oeste, asociados con cuatro herraduras orientadas hacia el Sur el día del solsticio de invierno y sobre un precipicio, en una inscripción

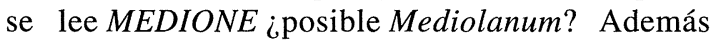
existe una tradición folklórica según la cual las herraduras corresponden a las huellas del caballo de Cristo, probable cristianización de una concepción real céltica reinterpretada sobre el «rey de reyes» (Spéranze, 1960).

\section{SistematiZaCión DE LOS ELEMENTOS COMPARATIVOS}

Llegados a este punto cabe establecer una comparación sistematizada en la tabla adjunta entre los ritos escocés, vasco y carintio para destacar semejanzas y diferencias. La idea que pretendemos destacar es que estamos ante una utilización medida, pensada, reflexiva, de una pequeña serie de variables que se actualizan según necesidades de coherencia ritual y coyuntura histórica pero, en los tres casos, bebiendo del mismo fondo céltico.

Veamos los elementos de cada fila con más detalle.

\begin{tabular}{|c|c|c|c|}
\hline & Escocia & Guernica & Carintia \\
\hline 1. protagonista & Señor & Rey de Castilla & Duque \\
\hline 2. vestido & blanco de poeta & campesino & $\begin{array}{l}\text { campesino, } \\
\text { después noble }\end{array}$ \\
\hline 3. pies & en piedra & $\begin{array}{l}\text { descalzo el } \\
\text { izquierdo }\end{array}$ & calzado humilde \\
\hline 4. atributos & vara blanca & lanza & $\begin{array}{c}\text { cayado de pastor, } \\
\text { espada }\end{array}$ \\
\hline 5. testigos & $\begin{array}{c}\text { Obispo, jefes de } \\
\text { familias principales }\end{array}$ & vizcaínos & $\begin{array}{c}\text { campesinos están, } \\
\text { nobles vienen }\end{array}$ \\
\hline 6. centro ritual & Piedra & Encina & Piedra \\
\hline \multicolumn{4}{|c|}{ Secuencia trifuncional del rito } \\
\hline 7. $3^{\mathrm{a}}$ función & no atestiguada & vestido campesino & simula compra \\
\hline 8. $2^{\mathrm{a}}$ función & en este caso, & arroja lanza & blande espada \\
\hline 9. $1^{\mathrm{a}}$ función & sí en otros & juramento & $\begin{array}{c}\text { juramento, } \\
\text { sobriedad, iglesia }\end{array}$ \\
\hline
\end{tabular}

1. El protagonismo del señor no requiere comentario.

2. Hay una oscilación en cuanto al grupo social sobre el que se fundamenta la soberanía. En Escocia se basa en la dimensión sacerdotal, el texto dice específicamente que el blanco pertenece al poeta (= druida) por derecho. Y el blanco es, genéricamente, el color de los sacerdotes indoeuropeos (Dumézil, 1958, 25-27 y 98). En Guernica y Carintia, sin embargo, el señor se presenta como campesino, aunque en Carintia después se viste como noble, acción que tal vez también se produzca en Guernica como atestigua un cuadro de Francisco de Mendieta que representa la investidura de Fernando el Católico como señor de Vizcaya (Delpech, 1997, 63-4). Es decir, se trataría de una soberanía asentada en la tercera función, cosa frecuente y subrayada por la simbología de los pies asentados sobre el territorio.

3. La simbología de la piedra sólo se atestigua en Irlanda, subraya la continuidad de la realeza en el tiempo. El pie descalzo del rey evoca la necesaria unión con la tierra, subrayando la aprehensión del espacio, además, por la carrera ante el árbol ${ }^{16}$; este aspecto es relevante en los ritos de Auvernia y la India. Se trataría, pues, de un subrayado de la dimensión temporal (Irlanda, Escocia) o espacial (Guernica, Auvernia, India) de la soberanía representado en la ideología indoeuropea por los denominados «soberanos menores»: Ariaman y Bhaga en la India, Juventus y Terminus en Roma, respectivamente (Dumézil, 1977, 96-110 y 171-6).

4. La naturaleza del objeto que lleva el señor en su mano es coherente con la estructura del rito. La vara blanca, relacionada expresamente con el poder de gobernar, es un atributo de la soberanía consonante con el vestido blanco (MacNeill, 1962, 295-6, indica que en York los sheriffs of the city portan bastones blancos el Lammas Day = Lugnasad). La lanza es, sin duda, guerrera en Guernica (infra) y el cayado, propio de un pastor como subraya Piccolomini, concuerda con el vestido campesino del duque. En cada lugar, además, este atributo tiene un valor diferente pero en cada caso orientado por una de las posibilidades abiertas por la ideología trifuncional. Es simple casualidad que tres situaciones tan distantes agoten precisamente ese abanico de opciones funcionales.

\footnotetext{
16 Delpech, 1997, 81-91. Kemp, 1992, 73-82, estudia la ceremonia llamada "abarcar el campo» en la que el faraón corre o camina a grandes pasos entre mojones situados en el patio del palacio que simbolizan el territorio egipcio. El contexto cultural del Egipto faraónico y la Vizcaya medieval es completamente diverso, pero la comparación señalada puede ayudarnos a comprender el sentido del gesto del rey de Castilla ante la encina.
} 
5. Este punto no requiere más que destacar la publicidad necesaria. Llama la atención la oscilación en nuestros testimonios: en Escocia se mencionan clero y nobles, en Carintia nobles y campesinos, cuando la totalidad social estaría representada por clero, nobles y campesinos como, por lo demás, en otros rituales indoeuropeos en relación con la realeza (Dumézil, 1986, 113-69; Dubuisson, 1978a). La mención a los 'vizcaínos' es muy pobre, pero en otros textos se especifica la presencia de toda la sociedad así en el momento de la jura de Fernando el Católico en Guernica (Caro Baroja, 1995, 269) o, de forma más significativa, en la jura de Enrique III de Castilla el año 1394, en donde se presenta una organización social tripartita en el árbol de Arechabalaga en una ceremonia de recepción del rey que después se desplazaría a Guernica (García Quintela, e.p.).

6. Sin duda es un elemento importante, no hay más que recordar lo que todavía representa el árbol de Guernica o la piedra de Scone para los escoceses. Recordemos la irlandesa piedra de Fal y su simbología y la relación etimológica entre diversos derivados de la raíz *art- estudiados por Guyonvarc'h (1967).

La secuencia trifuncional es un elemento común indoeuropeo (Dubuisson, 1978a). Pero hemos de descartar el testimonio escocés, pues no aparece la estructura trifuncional que está presente en otros testimonios de investidura real en Irlanda (Dubuisson, 1978b, 154-158). Es decir, se trata de una posibilidad presente que el texto que comentamos, o la realidad que recoge, no considera oportuno actualizar. En cuanto al carácter trifuncional de la secuencia vizcaína remitimos al estudio de Delpech (1997, 77-101). En el caso de Carintia los elementos trifuncionales se desdoblan en la promesa del duque: ser justo, dador de riqueza y defensor. Por otra parte el orden de los elementos funcionales es idéntico en Guernica y Carintia y recuerda el orden, también inverso, de las fases funcionalmente orientadas mediante las cuales Viriato consuma su boda, cuya relación con la soberanía se ha explicado en otro lugar (García Quintela, 1999, 193-211).

7. Se comienza con el elemento de tercera función, el vestido campesino y la solidaridad con la tierra del rey semidescalzo en Guernica y el simulacro de compra en Carintia. El simulacro de compra es típico, por ejemplo, de los matrimonios orientados por la tercera función.

8. El ritual guerrero no precisa que nos detengamos.

9. El acto obvio de primera función es el juramento, aunque el análisis de sus variantes sería muy complejo, véase infra algo más.

\section{ESTUDIO COMPARATIVO DE LOS PODO- MORFOS RUPESTRES}

Si ahora pasamos a Galicia, de toda esta serie sólo tenemos dos elementos seguros, la piedra y / o el árbol y la actitud respetuosa de quienes depositan cirios en su entorno. Dejábamos abierta, además, la posibilidad de que el rito en torno a la roca se relacionase con la observancia del pie. Este detalle en relación expresa con las piedras está presente de forma clara en el rito de investidura gaélico y de forma menos evidente en el ritual carintio. La presencia de la sociedad reunida es común en los tres casos traídos a colación. Finalmente, la ideología indoeuropea subyacente en todos estos rituales está claramente presente en el mundo galaico-lusitano a través de la leyenda de Viriato, personaje en torno al cual se han identificado una gran serie de episodios o relatos trifuncionales que terminan por situarlo en la esfera de la realeza (García Quintela, 1999, 213-22).

Pero en cuatro casos consideramos que las semejanzas son mucho más precisas y, al menos a nuestros ojos, sorprendentes:

\section{EL DOMINIO DEL ESPACIO}

En efecto, los podomorfos múltiples de Monteferro, con los pies dirigidos de forma que quien se sitúe sobre ellos abarca la práctica totalidad del horizonte, y de A Ferradura, con 11 pies orientados de forma que quien se coloque sobre ellos tenga una percepción plena del espacio circundante, concuerdan de forma muy estricta con el relato de investidura del Moistre en Auvernia y con el rito védico de «montar el espacio». Es más, el duque de Carintia en su investidura también se dirige a los cuatro puntos cardinales blandiendo su espada, rito que reaparece cristianizado en la ceremonia de investidura de los reyes polacos que, en un momento dado, dentro de la catedral, blanden la espada trazando una cruz en el aire en dirección a los cuatro puntos cardinales ${ }^{17}$. En la Irlanda medieval existen concepciones análogas sin relación directa con la investidura del rey (Le Roux y Guyonvarc'h, 1986, 304-5).

17 Gieysztor, 1990, 158. Es frecuente en las ceremonias medievales de investidura real que el rey manipule la espada, es peculiar de este caso la indicación de que blande la espada en las cuatro direcciones. Las descripciones o reglamentos de las ceremonias medievales de investidura son muy pormenorizados, por lo que el detalle indicado destaca más. No olvidemos que Galitzia es una región de antiguo poblamiento céltico inserta en los límites tradicionales del reino polaco. 
De una forma más genérica, todos los lugares de investidura real céltica que hemos reconocido se sitúan en alto. Lo mismo ocurre en el país de Gales. Es en una colina junto a Arberth, capital del reino de Dived, donde se celebra la investidura de los reyes (véanse los pertinentes episodios de los Mabinogi en Lambert, 1993, 42-45, 90-94).

\section{EL JURAMENTO}

En los monumentos galaicos estudiados, los podomorfos aparecen asociados siempre con otros elementos grabados en las rocas entre los que destacan cazoletas conectadas por canalillos (Monteferro, San Martiño y A Ferradura). Esta asociación material de insculturas tiene un paralelo en el rito descrito por Spenser, cuando el rey jura sobre la misma roca, cosa que también hace el alcalde de Brest y el duque de Carintia.

Para explicarlo podemos comenzar evocando el megarón del palacio micénico de Pilos. En su centro había un hogar y hacia el centro del muro nororiental estaba el trono del rey de frente al hogar.

«A la derecha del trono, se encontraron dos depresiones poco profundas unidas por un canal estrecho de unos dos metros de largo; la disposición es curiosa, pero Blegen sugiere que quizás servía 'para que el rey, sin bajar de su trono, vertiese libaciones a alguno de los dioses'» (Mylonas, 1966, 55).

No hay que descartar la función utilitaria del dispositivo, se trataría de no manchar el pavimento de la sala por lo que el canalillo conduciría el líquido en la dirección que no interfiriese con los asistentes a la ceremonia. Ahora bien, como ha demostrado Benveniste, muchas nociones indoeuropeas fundamentales llevan aparejada en su concepción inicial la realización de un gesto material que subraya y ejecuta o hace visible el valor conceptual de la noción dada. Esto ocurre, precisamente, con el juramento-libación, dice Benveniste, (1983, 363 y cf. $334-41$ sobre el juramento propiamente dicho):

«Un rito acompaña la prestación de un juramento o la conclusión de un pacto; es enunciado por el griego spéndo, 'hacer una libación', hitita sipant e ispant, es decir, spand-, de igual sentido, y el latín spondeo... En latín spondere es un término jurídico; en hitita spanddesinga una modalidad de sacrifico... completamente ausente del término latino. En griego spéndo asocia las dos significaciones que el hitita y el latín dan por separado: por un lado 'hacer una oblación líquida'; por otro 'concluir una convención'... Es, sobre todo, en griego donde se capta la relación con el juramento, cuando la spondé acompaña la prestación... Se presume, por tanto, que el sentido primitivo era el de una oblación líquida que consagra solemnemente un compromiso».
Por otra parte, las libaciones sobre rocas, con huecos específicos para ello están atestiguadas en el folklore de Escocia:

«Los montañeses de Escocia solían creer en una cierta hada llamada la Gruagach ... Se creía que en cada uno de los corrales de un caballero había de encontrarse uno o una Gruagach y que todas las noches había que dejarle un poco de leche en el hueco de una piedra especial que era guardada en el establo y llamada la piedra de la Gruagach ... Algunos afirman que sólo se derramaba leche en la piedra de la Gruagach cuando la gente partía para los pastos de verano, cuando regresaba de ellos, o cuando alguien atravesaba el establo con leche ..., todavía se pueden ver las piedras en las que se vertían las libaciones.» (Frazer, 1981, 313).

Podemos encadenar estos elementos para ofrecer una interpretación de la asociación entre podomorfos y piletas-canalillos. Por un lado, está el rey o jefe céltico que jura su cargo en pie sobre una roca ${ }^{18}$. Por otro, en Pilos tenemos huellas arqueológicas de la asociación del rey con la libación. Pero si la libación es el complemento gestual del juramento, como sugiere Benveniste para el estadio más antiguo, podemos entender los informes etnográficos célticos y el registro arqueológico de Pilos como la manifestación de dos dimensiones derivadas de un mismo acto primitivo. Teniéndolo en cuenta, pensamos que las piletas y canalillos que en Galicia acompañan a las huellas de pie, son la representación material de una libación (uso atestiguado en el folklore de Escocia) que se efectuaba, como parte de un juramento o sacrificio, no lo sabemos, en el momento de la investidura sobre esa misma roca.

\section{MonOSANDALISMO}

Es significativa la observación arqueológica de la diferencia entre pies calzados y descalzos atestiguada en Monteferro y A Ferradura, en San Marti$\tilde{n}{ }^{19}$ una cazoleta coincide con un pulgar. Este hecho merece una doble apreciación.

No es un hecho casual. Por medio de esa diferenciación se prescribe una forma de utilización del podomorfo que tenía un valor simbólico determinado. También permite considerar que la ceremonia en cuestión no era cotidiana.

Es decir, si muchas personas ejecutaban asiduamente un rito sobre estas insculturas no sería preci-

18 Entre los testimonios de juramento céltico recogidos por Le Roux y Guyonvarc'h, 1986, 135-8, y Kelly, 1988, 198-202, ninguno se relaciona con el rito de investidura real, aunque los pronuncien reyes y el juramento de éstos sea especial.

${ }^{19}$ Delpech nos recuerda que en Francia S. Martín o su caballo aparecen con frecuencia como los autores de las huellas de pie o herraduras inscritas sobre rocas. 
so recordar qué pie debían descalzar, sería algo comúnmente sabido. La precisión sobre el pie a descalzar es un útil mnemotécnico preciso para una ceremonia que se celebra en contadas ocasiones y sobre la que existe el mayor interés en que salga bien, que sus contenidos simbólicos se traten correctamente. Cabe evocar de nuevo, supra n. 17, la prolijidad de las descripciones de investidura real medievales pese a, o precisamente por, lo poco frecuente de su práctica.

Sobre el sentido del monosandalismo existe una abundante literatura comparativa y esperamos volver sobre él en otra ocasión. Indiquemos por el momento que posiblemente se relaciona con ideas sobre la hierogamia del rey con la tierra y / o la apropiación del espacio (Delpech, 1997, 87-91; Héritier-Augé, 1992; Campanile, 1981, 27-47).

ASOCIACIÓN CON HERRADURAS Y OTRAS HUELLAS DE CUADRÚPEDOS

Las improntas de bóvidos y posiblemente de cérvidos, están presentes en los petroglifos en Matabois y Pedra da Moura, las herraduras ${ }^{20}$ en Matabois y A Ferradura.

Las afinidades equinas del rey indoeuropeo son omnipresentes y los países célticos están muy bien representados en este particular. Se manifiestan desde su procedencia social de la clase guerrera, los caballeros, hasta el carácter específicamente real de los sacrificios de caballos, pasando por toda una mitología y folklore que atribuye al rey una fisionomía equina (Le Roux, 1963; Dumézil, 1986, 177 219; Milin, 1991). Esta asociación de formas tiene un paralelo formal muy próximo en una de las piedras del ónfalos secuano (Spéranze, 1960). Además esta asociación cuenta con paralelos en Irlanda (supra).

Es digna de mención, más en concreto, la pormenorizada descripción del sacrifico lusitano del caballo que nos ofrece Estrabón (III, 3, 6-7; García Quintela, 1999, 238-42). Por lo que las nociones anteriores no serían ajenas al mundo castreño, cosa representada además, como vemos, por la asociación pies humanos / herraduras en los petroglifos comentados.

Tal vez sea oportuno detenernos en el podomorfo de Campo de Matabois, acompañado, como

${ }^{20}$ No es seguro que estas figuras representen herraduras pero parece razonable considerarlas, con cierta reserva, representaciones de huellas de caballo. Consideramos el contexto en el que aparecen y sobre todo por la presencia de una escotadura en la base de la figura semicircular, elemento presente en las pezuñas de los equinos. otros, por huellas de cuadrúpedos tan esquemáticas y pequeñas que no permiten distinguir la especie representada, pero que es el único no orientado hacia el lugar de mayor visibilidad, sino hacia un pequeño rellano situado ante la roca, en un paisaje muy escarpado.

Pues bien, existe una modalidad de designación del rey de Irlanda tal vez legendaria, pues contrasta con los usos mencionados por E. Spenser citados más arriba. Se trata de la tairbfeis que se describe como sigue:

"A bull-feast is gathered (?) by the men of Erin, (in order to determine their future king) that is, a bull used to be killed by them and thereof one man would eat his fill and drink its broth, and a spell of truth was chanted over him in his bed. Whosover he would see in his sleep would be king» (Stokes, 1901, 22-3; cf. Le Roux y Guyonvarc'h, 1986, 76-7)

Si además del sentido de la huella en la roca, que estamos determinando, tenemos en cuenta que la traducción del microtopónimo es «Campo de Mata Bueyes», su asociación con ritos de realeza célticos parece clara. Sin poder afirmar nada, obviamente, sobre la modalidad de adivinación inspirada expresada en el testimonio irlandés.

\section{UN TESTIMONIO ETNOGRÁFICO PARA CONCLUIR}

Somos conscientes de la naturaleza del proceso intelectual para el que reclamamos la complicidad del lector. Pretendemos explicar objetos arqueológicos con ayuda de descripciones de corte etnográfico, de la Edad Media y posteriores, procedentes de toda una serie de áreas en las que se asentaron poblaciones célticas en la Antigüedad. El método puede ser discutible. En cualquier caso nos parecen claras y profundas las comparaciones establecidas. Parece como si las descripciones de hechos extrapeninsulares, en la pluma de autores muy diversos, tuviesen por escenario las rocas con podomorfos que estudiamos. Con todo, la innegable distancia espacio-temporal entre unas y otras sigue presente.

Pero el azar ha puesto a nuestra disposición un eslabón que une las descripciones extrapeninsulares con las peñas galaicas. Se trata de una noticia etnográfica sobre una roca peculiar recogida durante el seguimiento de las obras de construcción del gasoducto Irixoa-Neda ${ }^{21}$. En el ayuntamiento de $\mathrm{Ca}$ -

21 Trabajo realizado por el Laboratorio de Arqueoloxía das Formas Culturais de la Universidad de Santiago dentro del proyecto marco «Programa de Control e Corrección do Impacto Arqueolóxico da construcción da Rede de Gasificación de Galicia». 
banas (La Coruña), se encuentra un gran peñasco conocido como Pena da Elección que domina la desembocadura del río Eume. Sobre esa piedra una vecina cuenta que:

«antigamente, nesa pedra, elexíanse ós alcaldes, no alto da pedra existe a figura dun pé, a carón da pedra hai unha tumba, na noite de San Xoán oíase tocar a un gaiteiro» ${ }^{22}$.

Durante el transcurso de las obras y durante el estudio realizado como parte del Programa de Corrección realizado por Grupo de Investigación en Arqueoloxía da Paisaxe, pudimos observar la figura de un pie en la cima del peñasco. A diferencia de los descritos más arriba posiblemente haya sido formado por la erosión natural. Atendiendo al emplazamiento, la Pena da Elección, se sitúa en un punto dominante sobre el estuario del río Eume. La roca se localiza en la ruptura de pendiente sobre un pronunciado escarpe, lo que hace que, junto con su tamaño, destaque notablemente en el paisaje. La visibilidad desde el sitio, a pesar de su altura relativa, se limita al valle en el que se encuentra la villa de Pontedeume.

En cuanto al contexto arqueológico, el lugar guarda un estrecho paralelismo con el petroglifo de San Martiño, ya que la Pena da Elección se localiza muy próxima al Castro do Couto, parroquia de Salto, situado junto a un rellano altura. Mencionemos también que la Torre de los Andrade, medieval, está al otro lado del valle, en una posición análoga a la de Pena da Elección y erigida sobre una aglomeración rocosa.

Naturalmente, la noticia no menciona a reyes sino a alcaldes, pero recordemos que los reyes se desdibujan prácticamente en todas nuestras noticias (Captaine, Earl, Mouistre, Lord, Sheriff). En Brest, precisamente, encontramos la piedra donde jura su cargo el Maire. ¿Qué explicación daremos esta profunda analogía? ¿Hemos de reconstruir las vías por las que la anciana de Cabanas conocía el uso bretón atestiguado en un libro del siglo xvin?

Creemos que es más económica una explicación genética. En torno a la Pena da Elección ha fosilizado, como folklore, el conocimiento de antiguos ritos de investidura de corte céltico que probablemente se practicaron en la Galicia de la Edad del Hierro, como queda atestiguado por podomorfos de antigüedad segura. En favor de esta explicación genética está el texto de Martín de Dumio sobre pedem observare en relación con gestos rituales sobre rocas, a guisa de eslabón intermedio entre los pedi-

${ }^{22}$ Tradición recogida por M.J. Bóveda Fernández a quien agradecemos su comunicación. formes petreos y la noticia etnográfica. También es posible que el teónimo indígena Crougea Toudadigoe, que cabría interpretar como alto o roca de la comunidad política (por evitar el término tribu), forme parte del mismo ambiente ideológico (CIL, II, 2565 = IRG, IV, 91; CIL, II, 416).

Destaquemos otro dato: las noticias que integran nuestro material comparativo se han recogido entre los siglos XV y xx, estando su arcaísmo fuera de toda duda. Como lo está el arcaísmo de las leyendas en torno al rey de orejas de caballo pese a las diversas fechas de su compilación (Milin, 1991). Es decir, un rasgo constitutivo de las tradiciones que estudiamos es su persistencia, su acomodo sucesivo a contextos sociales e históricos cambiantes. En este sentido, tanto la información de Martín de Dumio como la noticia etnográfica sobre la Pena da Elección son homogéneas con el conjunto de nuestro dossier comparativo.

Para finalizar recordemos la fórmula con la que introduce el general romano S. Sulpicio Galba la mención al sacrificio de hombres y caballos que efectúan los lusitanos: suo rito inmolatis, es decir, no de las formas acostumbradas o conocidas por los romanos (Tito Livio, Per., 49; García Quintela, 1999, 229, 240-1).

Hemos de pensar, pues, que el rito de investidura real practicado entre los habitantes de los castros no sería igual a ninguno de los que conocemos gracias a los textos reunidos. Pero es verosímil que utilizase, en una combinación original, parte de los elementos conocidos por la comparación cuyas trazas desestructuradas en la antigua cultura galaicolusitana se han evocado: petroglifos podomorfos, reconocimiento del uso ritual de piedras y árboles, ideología indoeuropea de la realeza y más en concreto, la presencia sobre los monumentos comentados de asociaciones de formas que se pueden interpretar como plasmaciones físicas de aspectos del rito: visión amplia, juramento, monosandalismo, sacrificios.

Es obvio que sería deseable más información, relatos que permitiesen entender con mayor precisión los ritos y creencias que impelieron a las comunidades de la Edad del Bronce y Hierro a tallar rocas con trazos podomorfos. Pero carecemos de esos elementos. Entre tanto lo prudente parece ser la renuncia a tomar el objeto, el documento arqueológico bruto, por el todo y si, finalmente, otras explicaciones parecen mejores que las aquí avanzadas será porque también consideran ese objeto como parte de un todo más complejo.

No se nos escapa, por último, que de aceptarse el análisis propuesto sería necesario emprender nuevas 
investigaciones, algunas ya en distinto grado de elaboración. En primer lugar se debe volver a pensar sobre la estructura política de la sociedad castreña. También se impone una re-interpretación del fenómeno céltico en el noroeste peninsular cuando, si nos atenemos a criterios democráticos, nos encontramos con que la mayoría de los filólogos dice que el galaico-lusitano no es de familia celta. Sería necesario, además, abordar una explicación fundada en la historia de las religiones y la mitología, sobre el porqué de esos ritos y su simbología... trabajo a seguir.

\section{POST SCRIPTUM}

Estando en pruebas este trabajo hemos conocido el libro de Benito del Rey, L., y Grande del Brío, R., Santuarios Rupestres Prehistóricos en el Centro Oeste de España, Cervantes, Salamanca, 2000, donde se señala la presencia de insculturas pediformes en varios de los santuarios rupestres que estudian en la meseta Norte. Las referencias fundamentales son p. 69 fig. 9, San Pelayo, Almaraz de Duero; p. 73; p. 98 fig. 38, Santuario de Castro en Latada; pp. 1023 figs. 43 y 44, Peña Usende; p. 113 fig. 54, Santuario de Teso de San Cristobal en Villarino de los Aires; p. 121 figs. 62 y 63, Santuario de la Peña Gorda, La Ramajería; p. 123 fig. 55 y p. 125 figs. 66 y 68, Peña de San Martín en Iruelos del Mesón Nuevo; p. 133 fig. 77, Santuario de El Castillo en Vilvestre; p. 145 fig. 89, La Dehesa de Aldea Vieja. En un estudio posterior fijaremos el grado de similitud o diferencia con el registro arqueológico gallego aquí examinado.

\section{BIBLIOGRAFÍA}

Alföldy, G., 1997: Die Mysterien von Panóias (Vila Real, Portugal), Madrider Mitteilungen, 38, pp. 176-246.

Alonso del Real, C., 1971: Superstición y Supersticiones, Madrid.

Amado Reino, X., Martínez López, M.C., y Santos Estévez, M., 1998: La Arqueología en la Gasificación de Galicia 5: Corrección de Impacto del ramal Pontevedra-Ourense. Serie TAPA, 7. Santiago de Compostela.

Antonaccio, C.M. 1995: An Archaeology of ancestors: tomb cult and hero cult in early Greece, Lanham.

Benveniste, E., 1983: Vocabulario de las Instituciones Indoeuropeas, Madrid.

Bermejo Barrera, J.C., 1986: Mitología y Mitos de la Hispania Prerromana II, Madrid.
Boswell, J., 1974: Journal of a tour to the Hebrides with Samuel Johnson, R.W. Chapman (ed.), Oxford.

Briquel, D., 1983: Sur l'équipement royal indoeuropéen. Données latines et grecques, $R H R$, 200, 67-74

Búa Carballo, J. C., 1999: Hipótesis para algunas inscripciones rupestres del Occidente Peninsular, en F. Villar, F. Beltrán (eds.), Pueblos, Lenguas y Escrituras en la Hispania Prerromana, Salamanca, Zaragoza, 309-327.

Byrne, F. J., 1973: Irish Kings and High-Kings, Londres.

Calderone, S., 1972: Supertitio, ANRW, I, 2, 377 396.

Campanile, E., 1981: Studi di Cultura Celtica e Indoeuropea, Pisa.

Caro Baroja, J., 1995: Sobre el árbol de Guernica y otros árboles con significado jurídico y político, en Nosotros los vascos, IV, Bilbao, 265-282.

Castiglioni, L., 1970: Vestigia, Acta Archaeologica Academiae Scientarum Hungaricae, 22, 95-132.

CAstiglioni, L., 1971: Footprints of the gods in India and the Hellenistic Word, influence or parallelism?, Annales archéologiques de Syrie, 21, 25-36.

Costas Goberna, F.J., 1985: Petroglifos del Litoral Sur de la Ría de Vigo. Publicaciones del Museo Quiñones de León, 8. Vigo

Costas Goberna, F. J., Hidalgo Cuñarro, J.M., SoBRA J.M., ViÑas CuE, R., 1996: Raices de Nigrán, dende os petroglifos ata o Arco Visigodo, Nigrán.

Costas Goberna, F.J., Novoa Alvarez, P., y Albo Morán, J.M., 1991: Los Grabados rupestres de Gargamala (Mondariz) y el grupo IV del Monte Tetón en Tebra (Tomiño) provincia de Pontevedra, Revista Castrelos, 3-4, 86-116.

Costas Goberna, F.J., Pereira García E., 1998: Grabados rupestres en épocas históricas, Asociación Arqueológica Viguesa. Serie arqueología divulgativa, 4, 129-73.

Criado Boado, F., 1986: Serpientes Gallegas: madres contra rameras, en Bermejo Barrera, J.C., 1986, 241-274.

Criado Boado, F., 1993a: Límites y posibilidades de la Arqueología del Paisaje, SPAL 2, 9-56.

Criado Boado, F., 1993b: Visibilidad e interpretación del registro arqueológico, Trabajos de Prehistoria, 50, 39-56.

Criado Boado, F., 1989: Megalitos, espacio y pensamiento, Trabajos de Prehistoria, 46, 75-98.

Criado Boado, F., Santos Estévez M., Parcero OuBIÑA, C., 1997: Settlement patterns, land used and sacred landscapes in Galician Late Prehis- 
tory and ancient History: essay on an Archaeology Sacred Geographies, 11-9. Trabajos en Arqueología del Paisaje.

Delpech, F., 1997: Le rituel du 'Pied déchaussé', Monosandalisme basque et inaugurations indoeuropéennes, Ollodagos, 10, 55-115.

Deonna, W., 1926: Un omphalos: la 'pierre du milieu du monde', REA, 28, 180-182.

Díez de Velasco Abellán, F., 1998: Termalismo y Religión. La sacralización del agua termal en la Península Ibérica y el Norte de África en el mundo antiguo. 'Ilu., Monografías', $\mathrm{n}^{\circ} 1$, Madrid.

Dubuisson, D., 1978a: Le roi indo-européen et la synthèse des trois fonctions, Annales ESC, 33, 21-34.

Dubuisson, D., 1978b: L'équipement de l'inauguration royale dans l'Inde védique et en Irlande, RHR, 193, 153-164.

DumÉzIL, G., 1958: L'idéologie tripartie des IndoEuropéens, Bruselas.

DumÉzIL, G., 1986: Fêtes romaines d'été et d'automne, París.

DumézIL, G., 1993: Del Mito a la Novela, Madrid.

EiroA, J.J., Rey J., 1984: Guía de los petroglifos de Muros, Santiago.

Eliade, M., 1974: Tratado de Historia de las Religiones, I, Madrid.

ErkoreKa, A., 1995: Catálogo de «huellas» de personajes míticos en Euskal Herria, Munibe (Antropologia-Arkeologia), 47, 227-252.

Frazer, J.G., 1981: El Folklore en el Antiguo Testamento, México.

Funck-Brentano, F., 1953: El Antiguo Régimen, Barcelona.

García Alén, A., Peña SAntos, A., 1981: Los grabados rupestres de la provincia de Pontevedra, A Coruña.

García Fernández-Albalat, B., 1986: Las Llamadas Divinidades de las Aguas, en Bermejo Barrera, J.C.,1986, 141-192.

García Quintela, M.V., 1999: Mitología y Mitos de la Hispania Prerromana III, Madrid.

Gerber, P., 1997, The Stone of Destiny, Edinburgh.

GieyszToR, A., 1990: Gesture in the Coronation Ceremonies of Medieval Poland, en J.M. Bak, (ed.), Coronations. Medieval and Early Modern Monarchic Ritual, Berkeley, Los Ángeles, Oxford, 152-64.

GuARDuCCI, M., 1942-1943: Le impronte del Quo Vadis e monumenti affini, figurati ed epigrafic, Rendiconti della Pontificia Accademia di Archeologia Roma, 19, 305-344

Guyonvarc'H, Ch.-J., 1967: Notes de etymologíe et de lexicographie XXIX, 134. La «pierre», l' «ours» et le «roi». Gaulois artos, irlandais art, gallois arth. Le nom du roi Arthur, Celticum, 16.

Harmand, J., 1970: Les Celtes au second Age du Fer. Paris.

HAyes-McCoy, G.A., 1970: The Making of an O'Neill: a View of the Ceremony at Tullaghoge, Co. Tyrone, Ulster Journal of Archaeology, 33, 89-94.

Heesterman, J.C., 1957: The Ancient Indian Royal Consecration, La Haya.

Héritier-Augé, F., 1992: Moitiés d'homme, pieds déchaussés et sauteurs à cloche-pied, Terrain, $18,5-14$.

Kemp, B.J., 1992: El Antiguo Egipto. Anatomía de una civilización, Barcelona.

Kelly, F., 1988: A Guide to Early Irish Law, Dublín.

LAMBERT, P.-Y, 1993: Les Quatre branches du Mabinogi et autres contes gallois du Moyen Age, París.

LE Roux, F., 1963: Recherches sur les éléments rituels d'élection royale irlandaise et celtique, Ogam 15, 123-137 y 245-259.

Le Roux, F., Guyonvarc'h, Ch.J., 1995: Les Fêtes celtiques, Rennes.

Le Roux, F., Guyonvarc'H, Ch.-J., 1986: Les Druides, Rennes.

LeJeune, M., 1985: Recueil des incriptions gauloises, Textes gallo-grecs, Paris.

Lima, M., 1987: Fetishism, in Encyclopedy of Religions, vol. 5, 314-317.

López Cuevillas, F., Bouza Brey, F., 1929: Os Oestrimnios, os Saefes e a Ofiolatría en Galiza, A Cruña, (reimp. facs. Santiago, 1992).

López Cuevillas, F. 1958: Mitoloxía e historia da paisaxe de Trasalba, Homaxe a Ramón Otero Pedrayo, Vigo, 139-143

López Pereira, X.E., 1996: Cultura, Relixión e Supersticións na Galicia Sueva. Martiño de Braga, de Correctione rusticorum, La Coruña.

Loтн, F., 1915: L'Omphalos chez les celtes, REA, 17, 193-206.

Loтн, F., 1917: Lia Fáil ou pierre de Fál, pierre d'intronisation ou d'épreuve des rois d'Irlande a Tara. Omphalos ou phallus?, REA, 19, 3538

Loth, F., 1926: Cronique gallo-romaine, REA, 28, 265.

Llinares García, M., 1990: Mouros, animas, demonios. El imaginario popular gallego, Madrid.

MAC CANA, P., 1968: An archaism in Irish poetic tradition, Celtica, 8, 174-191.

Mac Cana, P., 1973: The Topos of the Single Sandal in Irish Tradition, Celtica, 10, 160-6.

MacNeill, M., 1962: The Festival of Lugnasa. A 
study of the Survival of the Celtic Festival of the Beginning of Harvest, Londres.

Marco Simón, F., 1993: Nemedus Augustus, en Adiego Lajara, I. J.; Siles, J.; Velaza Frías, J. J., (eds.) Studia palaeohispanica et indogermanica J. Untermann ab amicis hispanicis oblata, Barcelona, 165-177.

MiLin, G., 1991: Le roi Marc aux oreilles de cheval, Ginebra.

Molina García, J., 1989-1990: Podomorfos humanos en el complejo epilítico del Arabilejo. Yecla (Murcia), Anales de Prehistoria y Arqueología, 5-6, pp. 59-67.

Monteagudo García, L., 1943: El petroglifo de Fregoselo (Vigo-Corujo), Archivo Español de Arqueología, 52, 323-7.

Muir, K. (ed.), 1977: W. Shakespeare, Macbeth, Londres.

MylonAs, G.E., 1966: Mycenae and the Mycenaean Age, Princeton.

Newman, C. 1997: Tara. An Archaeological Survey, Discovery Program and the Royal Irish Academy, Dublín.

Newman, C. 1998: Reflections on the Making of a Royal Site, World Archaology, 30, 127-141.

PARCERo OubiÑA, C., 1995: Elementos para el estudio de los paisajes castreños del Noroeste Peninsular, Trabajos de Prehistoria, 52, 127-44.

Parcero Oubiña, C., Santos Estévez, M., y Criado BOADO, F., 1998: Rewriting landscape: incorporating sacred landscapes into cultural traditions, World Archaeology, 30, 159-76.

Pellicer Catalán, M., Acosta Martínez, P., HerNÁndez PÉrez, M.S., y Martín Cocas, D., 19731974: Aportaciones al estudio del arte rupestre del Sáhara Español (Zona Meridional), Tabo$n a, 2$.

Peña Santos, A., y Vázquez Varela, J.M., 1979: Los Petroglifos Gallegos, La Coruña.

Pérez Paredes, C.M., Santos Estévez, M., 1989: Gravados rupestres no concello de Arbo, Revista do Museo Municipal Quiñones de León de Vigo, 1-2, 51-80.

Piccolomini, E.S., 1998: La Europa de mi tiempo (1405-1458), prólogo, traducción, notas e índices de F. Socas, Sevilla.

PontFarcy, Y. de, 1987: Two Late Inaugurations of Irish Kings, Études celtiques, 24, 203-208.

ReEs, A. y B., 1961: Celtic Heritage, Londres.
Rodríguez Colmenero, A., 1999: O Santuário Rupestre Galaico-Romano de Panóias (Vila Real, Portugal). Novas achegas para a sua reinterpretaçâo global, s.l.

SANTOS Estévez, M., 1996: Los grabados rupestres de Tourón y Redondela-Pazos de Borbén como ejemplos de un paisaje con petroglifos, Minius, V, 13-40.

Santos Estévez, M., 1998: Los espacios del arte: construcción del panel y articulación del paisaje en los petroglifos gallegos, Trabajos de Prehistoria, 55, 73-88.

Santos Estévez, M.; Parcero Oubiña, C.; Criado BoAdo, F., 1997: De la arqueología simbólica del paisaje a la arqueología de los paisajes sagrados, Trabajos de Prehistoria, 54, 61-80.

SÉBILlot, P.-Y., 1950: Le folklore de la Bretagne, París.

SÉBILlot, P., 1983: Le folklore de France: la terre et le monde Souterrain, París.

Sobrino Lorenzo-RuZA, R., 1946: Los signos podomorfos del petroglifo de Santa Tecla y del mismo tipo conocidos hasta la fecha en Europa, El Museo de Pontevedra, IV, 131-4.

Spéranze, N., 1960: L'Omphalos Séquane de la Saône supérieure, Ogam, 12, 507-13.

Stokes, W., 1901: The Destruction of Dá Derga's Hostel, Revue Celtique, 22, 9-61, 165-215, 282329, 390-437.

SuÁrez Otero, X., 1979: Os Olleiros, nova estación do arte rupestre galego, El Museo de Pontevedra, XXXIII, 101-27.

TABOADA, J., 1957: El culto a los árboles en Galicia, en Homaxe a F.L.A. Cuevillas, Vigo, 125-134.

Taboada Chivite, X., 1965: O Culto das pedras no noroeste peninsuar, Verín.

VilaseCA, S., 1943: Los grabados rupestres esquemáticos de la provincia de Tarragona, AEspA, 16, 253-71.

VADÉ, Y., 1977: Sur la maternité du chêne et de la pierre, $R H R, 191,3-41$.

Vernant, J.-P., 1982: From Oedipus to Periander: Lameness, Tyranny, Incest in Legend and History, Arethusa, 15, 19-38.

Waddell, J., 1998: The Prehistoric Archaeology of Ireland, Galway.

W AILES, B., 1982: The Irish 'Royal Sites' in History and Archaeology, Cambridge Medieval Celtic Studies, 3, 1-29. 